\title{
LABOUR MARKET INSTITUTIONS AND INCOME INEQUALITY *
}

\author{
Daniele Checchi a \\ University of Milan and IZA
}

and

March 2008

\author{
Cecilia García-Peñalosa b \\ CNRS and GREQAM
}

\begin{abstract}
(n) 2008
Abstract. The recent debate on trends in inequality in industrial countries has been marred by the lack of consensus about the relevant concept of inequality. Labour economists are concerned with inequality in earnings, macroeconomists with movements in the wage share, while policy-makers tend to focus on household income inequality. We provide a unifying framework to study the relationship between these three concepts of inequality and their correlation with labour market institutions. Institutional measures exhibit significant associations with inequality, yet they play different roles depending on the extent to which they complement or substitute each other. As a result, we are able to propose a set of inequality minimizing institutions. Institutions that decrease inequality are, however, associated with higher unemployment, and our analysis explores the magnitude of this trade-off, and its implications if a common labour standard is imposed on members of the European Union.
\end{abstract}

JEL classification numbers: D31 (Personal Income, Wealth, and Their Distributions) - D33 (Factor Income Distribution)

Key words: income inequality, labour market institutions.

\footnotetext{
* Paper presented to the Economic Policy Panel meeting (Lubjana 18-19/4/2008). We thank Andrea Bassanini for providing some of the data and Silvia Redaelli for excellent research assistance. Daniele Checchi gratefully acknowledges the financing of the Italian Ministry of Education (Cofin n. 2005133811); Cecilia García-Peñalosa’s research was partly supported by the Institut d'Economie Publique in Marseille.

a University of Milan, Department of Economics, via Conservatorio 7, 20124 Milan, Italy. Email: daniele.checchi@unimi.it

b GREQAM, Centre de la Vieille Charité, 2 rue de la Charité, 13002 Marseille, France. Email: penalosa@ehess.univ-mrs.fr
} 
"The macro-economic theory of distribution has been little discussed in recent years, but should be revived. At the same time, once cannot read across directly from factor shares to the personal distribution. The experience of the UK, US and France suggests that the relation is one of some complexity."

Atkinson (2007)

\section{Introduction}

During the past two decades economists have been concerned with the apparent increase in various measures of inequality (see Atkinson, 2007). One of the striking aspects of this literature is the lack of consensus about how to measure inequality. Labour economists tend to focus on how the price of different types of labour changes over time, and hence have examined the evolution of hourly wage rates. Macroeconomists are concerned with the reward to different factors, that is, with the evolution of the shares of labour and capital in aggregate income. For policy analysts, the relevant concept is the distribution of household income, which combines capital income from different sources received by the household, the different labour incomes of household members, and government transfers, financed through taxation, which are often the main source of income of the poor.

These three commonly used measures of inequality need not move together. Figures 1 to 3 depict the trends in all three measures of inequality for the US, the UK, France and Germany over the period 1969 to $2000 .{ }^{1}$ Figure 1 depicts the Gini coefficients of gross household income, and shows that there have been increases in income inequality in all four countries, at least during the 1980s and early 90s. Figure 2 depicts a measure of inequality in wage incomes, the ratio of the wage of the $9^{\text {th }}$ decile of the wage distribution to that of the $1^{\text {st }}$ decile. The figure illustrates the extensively debated differences between the evolution of wage inequality in the Anglo-Saxon countries and in continental Europe. The US and the UK have experienced an increase in wage inequality starting, respectively, in the mid and late 1970s; in France the decile ratio fell initially and stabilized after the mid-1980s, while Germany saw little change over the period for which we have data. The third measure of inequality is captured by the share of income received by labour and that awarded to capital. Figure 3 reports trends in the share of wages in aggregate income. The labour share has been remarkably stable in the US, while the UK witnessed a decline over the period. ${ }^{2}$ France and Germany have experienced an increase in the labour share in the 1970s followed by a decline during the 1980s. In the last years of the century, the French labour share stabilized, while Germany saw a partial recovery of the share awarded to labour.

\section{Figures 1, 2 and 3 approximately here}

\footnotetext{
1 The Gini coefficient is our own computation using the Luxemburg Income Study data, the wage differential is from OECD (Trends in earning dispersion database) and the aggregate labour share is obtained from the OECD-Stan dataset.

2 The notable exception is the sharp increase and subsequent fall of the labour share during the labour government of $1974-$ 1976, after a period of major conflict between unions and the conservative government of Heath.
} 
These trends in inequality have led economists to put forward a number of different hypotheses to try to explain them. A common argument in the literature has been the role of differences in labour market institutions which have been argued to affect both the evolution of wage inequality and changes in the labour share. The aim of this paper is to analyse the way in which the various measures of inequality are related and the impact that labour market institutions have on them.

There is an extensive literature examining the effect of labour market institutions on labour market outcomes in industrial countries. This literature has documented that stronger institutions tend to increase unemployment rates and reduce the wage differential between high-skill and low-skill workers. By affecting the number of individuals with low incomes (the unemployed) and the relative incomes of different types of workers, labour market institutions will have an impact on the degree of household income inequality in an economy. Their effect is, however, ambiguous as higher unemployment rates will tend to increase overall inequality, while a more compressed wage distribution will tend to reduce it.

This paper provides a unified framework in which to examine the determinants of wage dispersion, the labour share, and the personal distribution of income. We argue that labour market institutions are the central element linking these three variables, and use data for OECD countries over the period 1960-2000 to evaluate the impact of institutions on these three forms of inequality. Our analysis involves three steps. First we estimate the correlation between institutions and household income inequality, using both reduced form and system estimation that allows us to identify the simultaneous variations of our different inequality measures. Our results indicate that stronger unions and a more generous unemployment benefit are associated with lower income inequality, while a higher tax wedge is correlated with a more dispersed distribution of income. Second, we quantify the size of these relationships and assess the extent to which certain institutions tend to move together so as to find a set of inequality-minimizing institutions. Third, we use the estimated coefficients to examine whether there exists a trade-off between inequality and unemployment induced by the functioning of labour markets.

A central aim of our analysis is to quantify the trade-off between inequality and unemployment. The results indicate that not all institutions engender such a trade-off, most notably the tax wedge. We find that a higher unemployment benefit replacement ratio and a lower degree of wage bargaining coordination are associated with higher unemployment and lower inequality. The magnitude of this trade-off is substantial, with an increase of one percentage point in unemployment being associated with a change in inequality of about one Gini point.

Our analysis can also help us understand the implications of implementing common labour market reforms across the European Union. First, we can assess the costs in terms of inequality of 
reductions in unemployment. Second, we show that reforms may induce a reduction in both inequality and unemployment in certain economies, and identify which countries would be the winners and which the losers if a common institutional set-up were imposed.

The paper is organised as follows. Section 2 we discuss the theoretical mechanisms that link institutions to income inequality, and review the relevant literature. Section 3 presents the data and examines the trends in inequality over the last four decades. Section 4 presents our estimates of the relationship between our two variables of interest. We then proceed to quantify the magnitude of the effect of institutions, and assess the combination that would minimize inequality. Section 5 performs a number of exercises using our estimates. In particular we assess the impact that the introduction of a common labour standard in the EU would have on inequality and unemployment. Section 6 concludes with a discussion of the political viability of initiatives against inequality.

\section{Why should labour market institutions affect the distribution of income?}

The institutional setup in which firms and workers operate is a crucial determinant of labour market outcomes, such as the unemployment rate, the relative wage between skilled and unskilled workers, and the share of aggregate income that is devoted to rewarding labour. These labour market outcomes, in turn, affect the distribution of household incomes, and hence provide a channel through which institutions ultimately impact on income inequality. For example, if the unemployed have lower incomes than those with jobs - as is the case even in countries with generous unemployment subsidies - then, the higher the fraction of the population that is unemployed, the more unequal the distribution of income is likely to be. In this section we discuss the theoretical arguments that underlie this hypothesis. We start with a review of the literature on the impact of labour market institutions on labour market outcomes, and then move on to examine the way in which the latter impact on the distribution of income.

\section{1. Labour market institutions and labour market outcomes}

Labour market institutions (LMIs) encompass different aspects of collective intervention, ranging from legal constrains and government policies to employee organizations outside the direct control of policymakers. Usually, six types of institutions are considered to define the institutional setup in which employers and workers interact, namely

\footnotetext{
* employment protection legislation,

* labour taxation, also called the tax wedge,

* the presence and size of a minimum wage,

* the unemployment benefit, measured by both its generosity and its duration,

* union density and coverage,
} 
* the degree of centralisation/coordination of wage bargaining.

In general, LMIs can be seen as providing income insurance against market forces and shocks, and an extensive theoretical literature has examined their effect on both wages and employment. ${ }^{3}$ The effect of stronger LMIs on labour market outcomes varies depending on the type of institution. Consider, to start with, the effect of a more generous unemployment benefit, whether in terms of a higher replacement ratio or longer duration. Unemployment insurance reduces search effort and increases reservation wages, resulting in fewer matches between employers and workers and in fewer offers being accepted, thus increasing unemployment. ${ }^{4}$ Moreover, the higher reservation wage implies higher wages on average. Higher labour taxation has a similar effect, although it acts on the demand side of the labour market. Because it increases labour costs for the employer, it will increase unemployment. If at least part of the labour tax is lump-sum, as is the case with some health or retirement contributions, it will also raise average wages since it is the least productive workers that will remain out of work. Lumpsum labour taxes will have a proportionally greater effect on low than on high wages and hence will also tend to increase the wage ratio between high- and low-earning individuals.

The impact of other institutions is a priori ambiguous. Unionization and centralised wage bargaining result in higher wages than those that would have prevailed in the absence of unions. If workers were paid their marginal product, this would tend to increase unemployment, but if there are rents to be split between labour and capital, higher wages need not imply more unemployed. The effect on wage dispersion depends on who is unionized (or covered by union agreements). Unionization is generally greater in the middle of the wage distribution, implying that stronger unions have an equalizing effect on the dispersion of wages across age and skill groups; see Card, Lemieux and Riddell (2004). Employment protection legislation reduces the risk of job loss, and shifts reallocation costs from workers to employers. As a result, employers refrain from firing in downturns but also from hiring in booms, and hence the overall effect on wages and employment is ambiguous. Similarly, a minimum wage need not reduce employment, which is determined by average wages; in addition it may also reduce the monopsonistic power of firms, thus raising employment among low-wage earners.

Overall, stronger institutions limit wage competition and eliminate low-wage employment. They all tend to increase average wages, reduce wage dispersion across industries, ages, and skills, and some of them also raise the unemployment rate. These predictions have been confronted with the experience of rich economies, which in the last three decades of the $20^{\text {th }}$ century witnessed either falling unemployment, stable real wages, and rising wage inequality - as was the case in Anglo-Saxon countries

\footnotetext{
3 See, for example, Blanchard and Wolfers (2000) for a discussion.

4 Actually, the policy results in a reduction in employment which, given labour market participation, in turn increases unemployment. However, there may be a negative effect of institutions on the labour supply as suggested by Bassanini and Duval (2006), among others.
} 
- or rising unemployment, rising real wages, and stable relative wages - a pattern observed in continental Europe. An extensive body of evidence indicates that changes in LMIs have played a central role in generating these different outcomes, with stronger institutions increasing unemployment rates and reducing wage dispersion; see Bertola, Blau, and Kahn (2002).

These well-established broad conclusions are the combination of various impacts stemming from different institutions. Concerning unemployment, there is consensus that a higher level and/or duration of the unemployment benefit and higher taxes on labour are associated with a higher rate of unemployment. However, there are conflicting results on the impact of employment protection legislation (EPL), trade union membership, and the structure of collective bargaining. For example, Nickel, Nunziata and Ochel (2005) and Bassanini and Duval (2006) find no statistical effect for EPL, while Bertola, Blau and Khan obtain a positive and significant impact on unemployment. Union density has no significant effect, while both Nickel and others and Bassanini and Duval find that greater wage coordination reduces unemployment. Moreover, the overall explanatory power of institutions is substantial, with LMIs explaining about $55 \%$ of changes in unemployment within countries, according to Nickell and others.

Studies on the determinants of wage dispersion indicate that strong and more centralized unions and minimum wages tend to compress the wage distribution, and this is apparent both in studies using aggregate measures of wage dispersion for a panel of countries and in those using microdata for a particular country; see Koeninger, Leonardi and Nunziata (2007) and Card, Lemieux and Riddell (2004). Instead, there seems to be no evidence of an effect of EPL, the tax wedge, and the generosity and duration of the unemployment benefit on wage dispersion.

The study of what factors drive changes in the wage share has received much less attention than the determinants of unemployment and wage inequality, whether in terms of theory or empirical evidence. Two notable exceptions are Blanchard (1997) and Bentolila and Saint-Paul (2003). Starting with an aggregate production function it is straightforward to show that the wage share will depend on the supply of production factors other than labour, hence empirical analyses have included a measure of the capital-labour ratio. A number of LMIs are also likely to have an impact on the wage share, as wage push factors are likely to increase it. The evidence indicates that factor shares respond to relative factor endowments (proxied by capital per worker) and to wage push factors - namely, union density with stronger institutions increasing the wage share.

An important problem with the evidence we have just reviewed, as well as with the approach we take in this paper, is that the results are based on cross-country data and hence provide correlations without being able to identify causation. A small body of work has tried to assess the causal effect of institutions on labour market outcomes using the differences in the timing of the introduction of legislation across US states. Autor, Kerr and Kugler (2007) find that employment protection legislation 
reduces employment flows, while Lee (1999) provides evidence that changes in the minimum wage were responsible for part of the increase in wage dispersion observed in the US during the 1980s. These results indicate that the correlations that the cross-country literature finds are likely to be due to institutions causing labour market outcomes.

\section{2. Labour market outcomes and income inequality}

We have just seen that the evidence indicates that stronger labour market institutions tend to increase the unemployment rate and the wage share and reduce wage dispersion. If labour market outcomes are a determinant of overall household income inequality, then LMIs will have an indirect impact on the latter. In this subsection we consider the way in which labour market outcomes affect income inequality, and hence provide a channel through which LMIs ultimately impact on the distribution of income.

To start with consider the effect of a higher rate of unemployment. Suppose an employed worker receives a wage $w$ while another worker with the same characteristics is unemployed and receives the unemployment benefit $B$. Since the unemployment replacement ratio is generally less than 1, then $B<w$, implying that the latter individual will have a lower income. A higher rate of unemployment will increase the fraction of individuals with low incomes and hence raise inequality. ${ }^{5}$ Greater wage dispersion will also tend to promote overall income dispersion as it increases inequality within the group of employed individuals. The effect of the wage share is however ambiguous. This is a standard effect when there is inequality within and between groups. Suppose that some individuals own wealth and hence receive capital income. The higher the share of capital is - i.e. the lower the wage share is - the greater inequality between capital owners and non-capital owners. However, a higher wage share raises inequality within the group of non-capital owners. To see this note that the contribution of wage earnings inequality to income inequality depends on two things: on earnings dispersion measured, for example, by the ratio of the wage of the top to the bottom decile or by the ratio of skilled to unskilled wages, and on the share of wages in total income. For a given degree of wage dispersion, the higher the wage share is, the greater the contribution of earnings inequality to income inequality will be.

\footnotetext{
5 This argument is correct as long as unemployment is not too high. For very high rates of unemployment, increasing the number of unemployed could reduce inequality. To see this, suppose that all individuals but one are unemployed and receive the same benefit; if this last individual looses her job and becomes unemployed all agents will receive the same income and inequality will fall. Clearly, this mechanism would require implausibly high unemployment rates.
} 


\section{Box 1 : The Gini coefficient in a model economy}

Suppose the labour force consists of $L$ unskilled individuals and $H$ skilled individuals. Individuals may work as skilled or unskilled workers, or be unemployed. Some individuals also own capital and receive profits. We also suppose that the owners of capital are always skilled workers, that they are never unemployed, and that they all own the same amount of wealth. Normalising the population to one, that is, $L+H=1$, we have four types of agents characterised as follows:

(i) A fraction $u$ of the labour force are unemployed, and receive the unemployment benefit $B$;

(ii) A fraction $l$ of the labour force are unskilled workers earning a wage $w_{u}$;

(iii) A fraction $s$ of the labour force are skilled workers. Of those $s-\kappa$ own no capital and have an income equal to the skilled wage $w_{s}$;

(iv) There are $\kappa$ skilled worker-capitalists, each of whom earns profits $\pi$ as well as the wage $w_{s}$.

Letting $y$ denote output per capita, we can then define the wage share as $\theta \equiv\left(w_{s} s+w_{u} l\right) / y$. Our assumptions imply that $s+l+u=1$, and that the profits of each worker-capitalist can be expressed as $\pi=(1-\theta) y / \kappa$. All wages and profits are subject to an employer (or employee) contribution, at rate $\tau$, implying that net wages are $\widetilde{w}_{s}=(1-\tau) w_{s}$ and $\widetilde{w}_{u}=(1-\tau) w_{u}$. These contributions are used to finance the unemployment benefit, so that $B=\tau y / u$. We further suppose that $\widetilde{w}_{u}>B$.

The degree of income inequality is measured by the Gini concentration index computed across the four groups of population. With four subgroups, the definition of the Gini concentration index is:

$$
\text { Gini }=\frac{1}{2 y} \sum_{i=1}^{4} \sum_{j=1}^{4}\left|y_{i}-y_{j}\right| \cdot n_{i} \cdot n_{j}
$$

where $y_{i}$ is the income in group $i$, which has relative weight $n_{i}$. There are three income concepts that we can use: factor income - comprising all income received from the market -, gross income, which ads to market income the benefits received from the state, and disposable or after-tax income.

Given our assumptions and denoting by $w$ the average wage, the Gini coefficient of factor income is given by

$$
\operatorname{Gini}_{f}=(1-\kappa)(1-\theta)+\theta\left(u+\frac{l s}{1-u} \frac{w_{s}-w_{u}}{w}\right) .
$$

The Gini coefficient is thus a function of population proportions $(u, l, s)$, the number of capital owners $\kappa$, the wage share $\theta$, and the wage differential. A greater wage differential between the skilled and the unskilled and a higher rate of unemployment raise the Gini coefficient. The effect of the wage share is ambiguous. This is a standard effect when there is inequality within groups (workers) and between groups (capital owners and non-capital owners). First, a higher wage share reduces the income differential between those who own capital and those who do not, as captured by the first term in equation (2); second, for any given dispersion of wages, $\left(w_{s}-w_{u}\right) / w$, a higher wage share increases the weight that the wage distribution has in total market income and raises inequality.

Turning now to gross income, we can express it as

$$
\operatorname{Gini}_{g}=(1-\kappa)(1-\theta)+u \theta\left(1-\frac{B}{w}\right)+\theta \frac{l s}{1-u} \frac{w_{s}-w_{u}}{w} .
$$

The only difference with the Gini index on market income is that inequality now depends also on the size of government transfers, which in our model economy take the form of an unemployment benefit. Lastly, disposable income is given by

$$
\operatorname{Gini}_{d}=(1-\tau)\left[(1-\kappa)(1-\theta)+u \theta+\theta \frac{l s}{1-u} \frac{w_{s}-w_{u}}{w}\right]-u \theta \frac{B}{w} .
$$


Lastly note that there is one labour market institution that will have a direct effect on income inequality: the unemployment benefit. Since the generosity and duration of the benefit determines the income of the unemployed, who are at the bottom of the income distribution, a higher benefit will reduce income inequality. These arguments are illustrated with a simple model presented in Box 1. As is common in the literature, our empirical analysis will measure the degree of income inequality by the Gini coefficient, ${ }^{6}$ and Box 1 derives an expression for Gini in an economy with four types of agents.

We can now turn to the impact of LMIs on income inequality. Putting together the arguments of this subsection and those discussed in subsection 2.1., the possible effects can be summarized as follows. Stronger labour market institutions

(i) have a direct effect on inequality, as a higher unemployment benefit reduces income dispersion, all else constant,

(ii) result in a higher rate of unemployment which in turn increases inequality,

(iii) result in less wage dispersion and hence reduce inequality,

(iv) result in a higher wage share which has an ambiguous effect on inequality.

The combination of these various effects implies that the impact of LMIs on the distribution of household incomes is a priori ambiguous.

Furthermore, the impact of LMIs will depend on the income concepts that we use. There are three income concepts that we can define, namely,

- factor income, comprising all income received from the market as either wage income, capital income, or self-employment income;

- gross or total income, which ads to market income unemployment benefit payments; ${ }^{7}$

- and disposable income, which is equal to gross income plus other (public or private) transfers and minus direct taxes.

The difference between the first two is that we would expect the unemployment benefit to have no direct effect on factor income, while a higher replacement rate should reduce total income inequality. Concerning disposable income, it should be affected by institutions in the same way as total income, but should also depend on a measure of the overall generosity and progressivity of the tax-transfer system.

\footnotetext{
${ }^{6}$ We have chosen the Gini coefficient as our measure of inequality in line with an extensive literature. There are, however, a number of other possible inequality indices that could have been used, such as the coefficient of variation or the Theil index. Different indices have different drawbacks and advantages. One of the features of the Gini coefficient is that it gives less weight than other indices to extreme observations - the very rich and the very poor. Household surveys usually have difficulties sampling these two groups, hence the Gini coefficient has the advantage of being affected less than other indices by the measurement problems at the extremes of the distribution.

7 The most frequent definition of gross income includes all transfers. Given our focus on LMIs we have chosen to include in our definition of gross income the only transfer that depends on LMIs, i.e. the unemployment benefit.
} 


\section{Box 2 : Cross-country evidence on the determinants of income inequality}

For decades, empirical work on cross-country differences in the distribution of income consisted of tests of the "Kuznets hypothesis" taking the form of regressions of inequality on the level of GDP and its square. Only recently have variables other than the level of income been considered, such as the level of human capital, the degree of democratisation, financial development, or the extent of dualism in labour markets. The evidence indicates that more democratic countries, better law enforcement, and greater financial development are associated with a more equal distribution of income, while a more segmented labour market is correlated with greater inequality; see Barro (2000), Bourguignon and Morrisson (1998), $\mathrm{Li}$, Squire and Zou (1998).

These variables have proven useful in explaining inequality in large cross-sections of countries with very different political institutions or at very different stages of development, but do not shed light on inequality patterns within the subset of rich, industrial countries. This is not surprising as, with the exception of education levels, all other variables show little variability across OECD countries. As a result, the literature on inequality patterns in rich countries has largely focussed on the effect of globalization, although results about its impact remain largely inconclusive. Existing work has generally neglected the role of labour market institutions, with the exception of Alderson and Nielsen (2002) who find a negative correlation between inequality and union density.

\section{Trends in inequality: Evidence from the Luxembourg Income Study}

\subsection{The data}

The main source of our data is the Luxembourg Income Study (LIS). The Luxembourg Income Study is a research project started in 1983 by researchers in several European and American countries in order to collect income, demographic, labour market and expenditure information at the micro-economic level in a way that is consistent across countries. Surveys are conducted every few years, and member countries have expanded over time, with the project now covering 30 countries. For our purposes the advantage of using the LIS data is twofold. First, as it is well known, the data on income inequality are problematic and international comparisons difficult (see Atkinson and Brandolini, 2001). Although some differences in methodology remain, the LIS data are the best source existing so far in terms of cross-country consistency. Moreover, having computed the inequality measures ourselves from the micro data, we have constructed them all according to the same criteria, rather than relying on summary measures computed by a national statistical agency.

Second, we are interested in measuring three sources of inequality. Existing work focusing on only one of these variables uses data from different sources: income inequality is computed from household surveys, wage inequality is derived from labour force surveys, while the labour share is 
obtained from national accounts. The problem of using different sources is that, as is well know, they may yield different values for the same variable. For example, it is well established that household surveys and national accounts give different levels and rates of growth for aggregate consumption; see Deaton (2005). There are various reasons for this discrepancy. Probably the most important ones are the fact that national account computations are based on quantities and then prices indices - which may not reflect the actual prices paid by consumers - are imputed, and the difficulty to sample correctly the very rich when undertaking household surveys, implying that they are under represent and hence the information on their consumption is poor. As Deaton points out, none of the data sources is "better" than the other, and the choice depends on the question to be addressed.

In our case, similar problems apply. Obtaining data on the very rich is problematic (although LIS oversamples high-income groups to try to improve on this aspect), while the capital share obtained from national accounts includes undistributed profits that are neither a reward to workers nor to capital owners. Although we have in principle the choice of using data from different sources, note that indices of income inequality can only be obtained from household surveys. To make our various inequality measures consistent with each other we hence compute them all from these surveys. Our choice has nevertheless a substantial cost. While data from national accounts and labour force surveys are available on an annual basis, the LIS performs surveys only every few years. As a result we have fewer observations than would be available if other sources were used, implying a trade-off between the quality of the data and the precision of econometric estimates. We have opted for the former at the expense of the latter. ${ }^{8}$

Our data set covers 17 industrial countries over the period 1969 to 2004. Details on the data and their sources are provided in the Appendix, and descriptive statistics are reported in table A.1. The number of observations varies across countries, depending on the number and frequency of surveys, with countries having between 3 and 8 observations spread over the sample period. The US, the UK, Italy, Germany, and Canada have the most observations. ${ }^{9}$ All measures concern household income. We obtain the Gini indices for factor or market incomes, gross or total incomes, and disposable income. Wage income inequality is measured by the ratio between the income of the $90^{\text {th }}$ and the $10^{\text {th }}$ percentiles of the earnings distributions, denoted by $\mathrm{p} 90 / \mathrm{p} 10 .{ }^{10}$ These measures capture inequality at the top and at the bottom of the wage distribution. Lastly, the wage share is computed as the fraction of labour income onto the sum of labour and capital income (including self-employment), computed at

\footnotetext{
${ }^{8}$ In Checchi and García-Peñalosa (2005) we take the opposite approach.

${ }^{9}$ Data were available also on the Czech Republic, Greece, Hungary and Poland. We excluded the former two because we had only two inequality observations, and the latter because of the limited information on labour market institutions..

${ }^{10}$ In an earlier version of the paper we experimented with different decile ratios (between the $90^{\text {th }}$ and the $50^{\text {th }}$ and between the $50^{\text {th }}$ to the $10^{\text {th }}$ percentiles). Results were similar with the $\mathrm{p} 90 \mathrm{p} 50$, while being statistically very poor for the $\mathrm{p} 50 \mathrm{p} 10$.
} 
household level, and then averaged over families, using household weights (see the Appendix for the details).

\subsection{Inequality trends}

Figures 4 to 6 depict the evolution of our variables of interest computed from the LIS. Figure 4 reports our measures of household income inequality, computed over the three income concepts factor, total and disposable income. The figure indicates that the last three decades of the 20th century witnessed an increase in income inequality in many industrial countries. The exceptions in our sample are Austria, Ireland and the Netherlands. Switzerland is unusual in that the 1990s witnessed a large increase in factor income inequality, but a reduction in total and disposable income inequality. A second feature of the data is the large impact that transfers have on inequality. On average, transfers through the unemployment benefit reduce inequality by 5 Gini points, although there is a large variation in the effect across countries. In the US, but also in Australia, Germany and Italy, transfers reduce the Gini coefficient by only 2 points, while in Scandinavian countries inequality falls by between 7 and 9 points.

Focusing on disposable income, we can see that the overall impact of taxes and transfers on distribution can be large, and indeed these account for a large fraction of cross-country differences in income inequality. For example, in the year 2000 the Gini coefficients of factor income were roughly the same in Canada and the US (0.38 and 0.39 respectively in our dataset), while slightly lower in Finland (0.36). However, the Gini coefficient of disposable income was much higher in the US than in the other two countries (0.33 in US, 0.30 in Canada and 0.26 in Finland - see also Brandolini and Smeeding, 2007). Overall, the data displays more variability in factor income inequality than in total or disposable income inequality.

\section{Figures 4, 5, and 6 approximately here}

Figure 5 reports three wage percentile ratios, which are the p90/p10, p90/p50, and p50/10. We can observe the well-known increase in the p90/p10 ratio in the US, the UK, and Canada, but also evidence of an increase in wage inequality in Germany, especially after 1990. The Scandinavian countries present very different patterns, with Denmark and Norway exhibiting rather stable p90/p10 ratios, and Sweden and Finland experiencing a sharp increase in wage inequality up to 1995 and a decline thereafter. The sources of the increase in the $\mathrm{p} 90 / \mathrm{p} 10$ ratio differ across countries. In the US it is the result of an increase in both the p90/p50 and the p50/p10 ratios, while in Sweden it has been caused by a sharp increase of inequality at the bottom of the earnings distribution. ${ }^{11}$

\footnotetext{
11 We would like to point out the high value of the decile ratio observed in Spain in 1980. Since many other institutional variables records high values (for example the union membership drops from 44.7 in 1979 to 19.2 in 1980 and 8.34 in 1981)
} 
Figure 6 depicts the wage share obtained from two sources, the LIS micro-data and macro-data obtained by the OECD from national accounts. As is well-known the share of wage income in household income is substantially higher than the share of wages in corporate value added; see Piketty (2003). For example, in the US, the share of wages in household income is, on average, 83 percent while the aggregate wage share is 58 percent. There are two reasons for this difference. The first one is that there are undistributed profits that are classified as capital income in national accounts but are not received by households; the second is that both capital income and self-employment income tend to be underreported in micro surveys, hence increasing the wage share in household income. We can see in the figure that the levels and trends of the wage share differ substantially across countries. Some countries show rather stable wage shares, such as Canada, Denmark and the US. In Italy both the aggregate and the LIS wage share show a sharp decline, while in France there was a large reduction in the share of wages in household income but a much smaller one in the aggregate wage share.

\section{Income inequality and labour market institutions}

\subsection{Empirical strategy}

There are two elements in our analysis. First, we have argued that the Gini coefficient of household incomes can be expressed as a function of the wage share, wage inequality, unemployment and the replacement rate. Hence we will estimate the following relationship

$$
\text { Gini }_{i t}=g_{0}+g_{1} \cdot \theta_{i t}+g_{2} \cdot \omega_{i t}+g_{3} \cdot \theta_{i t} \cdot \omega_{i t}+g_{4} \cdot u_{i t}+g_{5} \cdot b_{i t}+g_{6} \cdot b_{i t} \cdot u_{i t}+\delta_{i}+\tau_{t}+d e f_{i t}+\varepsilon_{i t}
$$

where $\theta_{i t}$ denotes the labour share, $\omega_{i t}$ is a measure of wage inequality, and $u_{i t}$ the unemployment rate for country $i$ in year $t$. The unemployment benefit replacement ratio is denoted $b_{i t}$ and will not be included when estimating the equation for factor income. We also control for different definitions used to compute the Gini index with the variable $d e f_{i t}, 12$ and include country (or region fixed) effects, $\delta_{i}$, and time fixed effect, $\tau_{t} \cdot{ }^{13}$

The coefficient $g_{1}$ captures the relative contribution of the factor distribution of income to household income inequality, $g_{2}$ measures the contribution of wage inequality to overall inequality, while $g_{3}$ allows for an interaction between these two variables. The coefficients $g_{1}, g_{4}, g_{5}$ and $g_{6}$ can be interpreted as a measure of the between-group inequality, where groups are to be defined in accordance to their position in the production process: owners of capital versus those who do not, and

in those turbulent years, we take them with some caution and report estimates both including and excluding observations on Spain. See below.

12 This variable is a dummy taking the value 1 for countries that report net rather than gross wage income.

13 Given the discontinuous nature of inequality measures obtained from LIS, it is impossible to use a year fixed effect, and we have included decade fixed effects. 
the employed versus the unemployed. Meanwhile, $g_{2}$ and $g_{3}$ can be interpreted as the contribution of within-group inequality, caused by the fact that employed workers receive different incomes. For a given degree of wage inequality, the higher the wage share is, the greater the contribution of withingroup inequality to total inequality will be. We expect $g_{2}, g_{3}$ and $g_{4}$ to be positive, $g_{5}$ and $g_{6}$ to be negative, while $g_{1}$ has a priori an ambiguous sign.

Second, labour market outcomes depend themselves on LMIs. Hence, we can express the labour share, the wage differential, and the unemployment rate as

$$
\begin{aligned}
& \theta_{i t}=a_{0}+a_{1} \cdot \gamma_{i t}+a_{2} \cdot \mu_{i t}+\delta_{1 i}+\tau_{1 t}+\varepsilon_{1 i t} \\
& \omega_{i t}=c_{0}+c_{1} \cdot \gamma_{i t}+c_{2} \cdot \mu_{i t}+\delta_{2 i}+\tau_{2 t}+\varepsilon_{2 i t} \\
& u_{i t}=d_{0}+d_{1} \cdot \gamma_{i t}+d_{2} \cdot \mu_{i t}+\delta_{3 i}+\tau_{3 t}+\varepsilon_{3 i t}
\end{aligned}
$$

where $\gamma_{i t}$ is a measure of the strength of labour market institutions and $\mu_{i t}$ captures additional factors, such as investment, trade openness, educational attainment, age of household head, and female labour force participation, that are expected to affect labour market outcomes. Once again, the variable $\delta_{i}$ denotes a country/region fixed effect and the variable $\tau_{t}$ represents a decade fixed effect.

Equations (2) to (4) imply that the components of inequality are endogenous, and hence the coefficients obtained when estimating equation (1) under OLS may be biased. In order to obtain unbiased estimates we can follow two procedures. The first one consists of estimating equation (1) instrumenting for labour market outcomes, with LMIs being the obvious instruments. We will hence estimate the simultaneous equation system given by equations (1), (2), (3) and (4) through three-stage least squares methods (3SLS). Alternatively, we can focus on the reduced form equation obtained when we replace (2)-(3)-(4) into equation (1), which yields

$$
\text { Gini }_{i t}=h_{0}+h_{1} \cdot \gamma_{i t}+h_{3} \cdot \mu_{i t}+\delta_{i}+\tau_{t}+d e f_{i t}+\varepsilon_{4 i t}
$$

In the reduced-form equation the overall effect of labour market institutions is mostly ambiguous due to the conflicting impact occurring through the three labour market outcomes.

We proceed to illustrate the effect of institutions in three steps. We start with an OLS estimation as a first approach to explore the correlations between labour market outcomes and income inequality. We will then introduce a 3SLS estimation, followed by the estimation of the reduced-form equation. The reason to obtain both system and reduced-form estimates is that they give us different types of information. In particular, 3SLS will allow us to understand the particular mechanisms through which LMIs impact inequality; while the reduced form equation quantifies the overall effect of a particular institution but does not allow us to identify through which labour market outcome it is operating and hence makes it difficult to understand the trade-off involved in policy changes. 


\subsection{Income inequality and labour market outcomes}

We start by estimating equation (1) using the three different concepts of income: factor incomes, total gross incomes and disposable income.

When we analyse the correlation between labour market outcomes and income inequality, we are confronted with the limited number of observations available per country, which corresponds to the waves available in the LIS data set. The number of observations with non missing values is limited (88 at best), although we cover the 17 countries rather evenly, with an average number of observations per country slightly exceeding five. In addition to labour market outcomes, we also include in our regression for inequality a number of factors that are likely to affect income distribution. These include characteristics of the population, namely, education (measured by the fraction of household heads with some tertiary education), the female share in employment, the average age of household head and of spouse, and two macroeconomic variables, physical capital accumulation (proxied by investment over GDP) and trade openness (measured by imports + exports over GDP).

Table 1 reports the OLS estimates for the three income definitions. The first three columns report various specifications for factor income inequality, while columns 4 to 6 present the estimated coefficients for total income. As discussed above, when we move onto disposable income we need to include some measure of the size of the welfare state, which we proxy by the share of social security transfers in GDP. We lack data on this variable for Spain, hence the last six columns of the table report the results for a reduced sample that excludes Spain, with total income inequality in columns 7 to 9 and disposable income inequality in columns 10 to 12 . In each equation we control for country fixed effects, decade fixed effects and income definitions.

We can see that whether we use our measure of the labour share computed from LIS or the one obtained from aggregate data by the OECD, we find only weak evidence of a negative correlation between the labour share and inequality. On the contrary, when considering the equation for factor income, both the decile ratio and unemployment present positive and significant coefficients. Inequality is also higher when the population is older and more educated. Note that the decile ratio could be high either because there are a large number of individuals with high wages, or because the skilled-unskilled wage ratio is large. We are controlling for the fraction of household heads with tertiary education, implying that the coefficient on wage dispersion is probably capturing the impact of the skill premium on overall income inequality.

When we consider total income inequality, we find weak and unstable evidence of a correlation between inequality and labour market outcomes. Only the unemployment rate and the unemployment benefit seem to have a significant effect across the two samples. As with factor income, a more educated population is associated with greater inequality, while greater trade openness is negatively correlated with inequality. The results for disposable income reported in the last three columns also fail 
to identify a strong relationship between inequality and our variables of interest. For example, the first two formulations find a significant coefficient on the decile ratio, but when interacted with the wage share, only the latter remains significant. The size of the welfare state also has an insignificant coefficient, while the female share in employment, education and openness are all significantly correlated with inequality.

\section{Table 1 approximately here}

As we have discussed, the OLS estimates are potentially biased, hence we proceed to estimate the system of equations (1) to (4) through 3SLS. Table 5 reports the results; the system is estimated both including and excluding Spain (columns 1 to 4 and column 5 to 8, respectively). The structure of this semi-reduced form system is recursive, since all (but one) labour market institutions affect the intermediate inequality components only (columns 2 to 4 and 6 to 8), and these intermediate components then determine total income inequality (columns 1 and 5). We include the measures of the strength of labour market institutions discussed above. We measure union presence by union density and the degree of bargaining coordination, and the minimum wage by the so-called Kaitz index (the ratio of the minimum wage to the median wage of an average worker). We also include the unemployment subsidy, measured as the gross replacement rate averaged over initial and final years, the tax-wedge, and employment protection legislation. ${ }^{14}$ Our approach is to instrument the wage share, the decile ratio and the unemployment rate with our six measures of LMIs. We consider labour market institutions as exogenously given, even if we are aware of their potential endogeneity in the long run. ${ }^{15}$ In order to minimise the bias induced by neglecting endogeneity, we use lagged values of the predetermined variables. Given the discontinuous nature of our dependent variables, it is impossible to assess the optimal lag length using standard criteria, such as the Akaike information criterion. We have therefore resorted to a conventional time lag of one year, but results are almost identical if we adopt a two-year time lag. In the selection of the preferred model we have followed the results obtained from estimates of the determinants of the wage share, the earnings differential, and the unemployment rate. The diagnostic statistics obtained from the 2SLS reported in the Appendix (tables A.3 and A.4) raise the issue of controlling for other unobservables in the country institutional setup. Given the limited number of observations per country, and the reduced variation of institutional measures overtime

\footnotetext{
14 In previous version we have also considered additional institutional variables (like union coverage, wage bargaining centralisation, strike activity, active labour market policies) but country/year coverage was limited, and therefore we have decided to dispense of them.

15 This assumption is not without problems, since also the unemployment benefit is potentially endogenous, since it typically exhibits a positive correlation with the unemployment rate. If the generosity of the benefit is decided under majority voting, the greater the risk of unemployment among voters, the higher the chosen benefit will be (Saint-Paul, 2000), thus generating a revere causality link between the two variables.
} 
(especially for employment protection and wage bargaining) if we were to use country fixed effect we would shift most of the explicative power on these fixed effects, especially when one considers that we are also controlling for decade variations. We consider this strategy too demanding on our sample, and for this reason we introduce regional rather than country fixed effects, with the regions being NorthAmerica, Anglo-Saxon (excluding Canada and the US), Scandinavian, and Continental Europe. Diagnostic tests suggest that the whole set of LMIs is appropriate as instruments when we use regional controls, while they becomes inappropriate (at least for the two first stage equations concerning wage share and decile ratio) according to common standards when we use country fixed effects (see tables A.3 and A.4 in the Appendix). The overidentification test for the instrument at the second stage reject the $\mathrm{H}_{0}$ in almost all the specification. ${ }^{16}$ For these reason we have chosen to proceed with regional and decade controls. We report the results for total income inequality; those for the other two measures of inequality being qualitatively similar.

The estimated regression for the Gini coefficient indicates that a higher wage share and higher unemployment rate are, respectively, negatively and positively correlated with inequality. The negative coefficient on the wage share indicates that the effect of inequality across groups (those who own capital versus those who do not) is more important than that of inequality within the group of employed individuals. The unemployment benefit has an insignificant coefficient, while that on the decile ratio has the expected sign, but is unstable, being significant only when we exclude Spain. Note, however, that in this case our model seems unable to explain any of the variability in the decile ratio, as can be seen from the fact that all coefficients in column 7 are statistically insignificant. The estimated coefficients differ markedly from those obtained in the OLS estimations, indicating that the estimates in table 1 are biased. ${ }^{17}$

Consider now the equations for the three labour market outcomes. ${ }^{18}$ Both columns 2 and 6 report a positive correlation between the wage share and union density, and a negative one with the coordination of wage bargaining. A possible explanation for this is that greater coordination implies wage negotiations that cover a large number of sectors of industries and this makes it harder to push for higher wages across the board. As a result, wages and hence their share in income tend to be lower.

\footnotetext{
16 There is an additional reason which advises against country fixed effect, that is the limited degrees of freedom. If we were to use 16 country fixed effects in a 4 equation system estimation with 86 observations, we were almost close to exhaust all degrees of freedom available.

17 These results are rather robust against country exclusion. However, when we exclude the Nordic countries (Finland, Norway and Sweden) or Italy and Switzerland, the estimated coefficient on the decile ratio becomes significant, but according to the Hansen test the set of instrument tend to be overidentified.

18 We have achieved the current specification starting from the full set of LMI (as in the 2SLS) and gradually removing the statistically insignificant regressors, while respecting the identification restrictions. In the present specification, the wage share equation is identified by the employment protection legislation, the decile equation by the minimum wage legislation (and by trade openness - not shown in table 2) and the unemployment equation by the tax wedge (and by investment/GDP ratio - not shown in table 2).
} 
In addition, employment security (granted by employment protection legislation) tends to lower the wage pressure exerted by unions. Interesting results emerge when we consider the possibility of institutional complementarities (see Belot and van Ours, 2004, and Blanchard and Wolfers, 2000). We interact employment protection with unemployment benefits, two alternative institutions to cope with the income risk caused by the threat of unemployment (Blanchard and Tirole, 2004). Theory tells us that wage pressure (and the wage share) is lower when workers are protected in the workplace (higher employment protection) or in the market (higher unemployment benefit). Our results indicate that the co-existence of both protections tends to increases wage pressure. Altogether, the estimated coefficients in columns 2 and 4 of table 2 suggest that the share of wages in household incomes tends to be higher when unions are powerful but uncoordinated (Calmfors and Driffill, 1988), and when workers are less protected in the labour market.

Column 3 of table 2 indicates that union presence is also relevant for wage compression, consistent with the fact that unionization tends to be greater in the middle of the wage distribution and hence leads to wage compression, and in line with existing in evidence. We also find that the top/bottom decile ratio is negatively associated with the minimum wage. These coefficients are, however, unstable. Removing Spain from the sample makes them lose all significant and yields a regression equation in which none of the LMIs is correlated with the decile ration. These results contrast with a significant impact found in other studies. A possible explanation for these differences is that the nature of the data is not the same. Most studies on the determinants of wage inequality use data obtained from labour force surveys, which often cover only full-time workers and define the wage differential in terms of hourly wage rates. Our data, obtained from household surveys, includes all households with non-zero labour incomes, equalises them according to family size, and the wage ratio is calculated over annual rather than hourly earnings.

Concerning the determinants of unemployment (columns 4 and 8 of table 2), we have followed the traditional approach of including measures of labour costs (captured by the tax wedge), work incentives (proxied by unemployment benefit), and wage bargaining. ${ }^{19}$ Consistent with most of the literature, we find that the unemployment rate is positively correlated with the unemployment benefit and the tax wedge. We find only weak correlation (significant at 13\%) with the degree of coordination of bargaining, in contrast to Nickell and oths. (2005) and in Bassanini and Duval (2006) who find stronger evidence that unemployment tends to be higher when wage bargaining is less coordinated.

Our model has an overall good fit, as indicated by the standard statistics (Root Mean Square Error and $\mathrm{R}^{2}$ ) reported at the bottom of table 2. However, given the discontinuous nature of our series

\footnotetext{
19 While in principle we could have computed the unemployment rate from LIS microdata, in practice we had only information on the household and spouse status, and not for all the surveys. The resulting data were rather unsatisfactory, and we decided to rely on the aggregate variable, obtained from OECD labour force statistics.
} 
for inequality, we have not imposed any structure on the adjustment dynamics, which prevents our model from capturing well the cyclical fluctuations which, for example, are evident in the evolution of the wage share and, to a lesser extent, of the unemployment rate (graphs of the predicted values for all years available are reported in the Appendix II - see figures A.1-A.2-A.3-A.4).

\section{Table 2 approximately here}

Putting together the results from our four equation system, and being aware that our regressions can capture a causal relationship if and only if our LMIs were fully exogenous, we can examine the different impact that the various institutions have on inequality. Our estimates indicate that:

(i) a higher tax wedge and a higher unemployment benefit increase inequality through their impact on the unemployment rate;

(ii) greater union density results in lower inequality, as it tends to reduce the labour share, which results in a less dispersed distribution of income;

(iii) the coordination of wage bargaining reduces the labour share, raising inequality;

(iv) the effect of stronger EPL is ambiguous, and the overall effect depends on the size of the unemployment benefit;

(v) we find no effect of the minimum wage on labour market outcomes and hence none on inequality.

\subsection{Income inequality and labour market institutions: reduced form estimates}

An alternative way of examining the relationship between LMIs and inequality is to estimate a reduced form equation. As argued before, this has the advantage of allowing us to estimate the overall impact of institutions. OLS reduced-form equations are reported in table 3 for our three measures of inequality. ${ }^{20}$ Columns 1 to 3 report the regressions results for the entire sample. The equation for factor income, column 1 , indicates only a weak role for institutions, with the tax wedge being the only variable that has a significant coefficient. Institutions have a much stronger impact when we consider inequality in total and disposable incomes. Union density is negatively correlated with inequality, and the tax wedge positively correlated, in line with the results obtained in the 3SLS estimation. Also consistent is the fact that we find no effect of the minimum wage. We find no evidence of a correlation between wage bargaining coordination and inequality, in contrast to the positive correlation implied by the 3SLS

\footnotetext{
${ }^{20}$ Here again we use regional fixed effect. In table A.5 we report country fixed effects estimates, where only the effect of employment protection legislation and tax wedge exhibit statistically significant effects. When we compare country fixed effects to the alternative of random effects, the Hausman test indicate that the first alternative is preferable to the latter.
} 
estimates. One possible explanation for this is that the reduced-form equation is capturing the effect of coordination operating through the unemployment rate. In table 2 the coefficient on wage bargaining coordination is significant at the $13 \%$. The negative coefficient implies that greater coordination reduces unemployment, which in turn reduces inequality. This effect offsets the impact operating through the wager share, resulting to an overall insignificant effect. Lastly, the impact of the unemployment benefit and employment protection legislation are closely related, with a higher benefit increasing inequality only if employment protection is not strong. Equivalent results are obtained when Spain is excluded (columns 4 to 6 )

\section{Table 3 approximately here}

Columns 7 to 10 of table 3 estimate the reduced form model by regions, aggregating the countries in three large regions: "Anglo-Saxon" (Australia, Canada, Ireland, Switzerland, United Kingdom, United States), "Scandinavia" (Denmark, Finland, Norway, Sweden) and "Continental Europe” (Austria, Belgium, France, Germany, Italy, Netherlands, Spain). The so-called liberal market economies (Hall and Soskice 2001) are characterised by some correlation between income inequality, minimum wage legislation, and unemployment benefit, but are completely unaffected by union presence, as can be seen in column 7. Despite the small sample, the equation for Scandinavian countries presents coefficients which are close to those obtained for the entire sample. In the continental Europe economies, inequality is correlated with employment protection legislation (negatively) and with the tax wedge (positively). Both coefficients are much larger for this group of economies than for the entire sample.

\subsection{Evaluating the association between labour market institutions and income inequality}

\subsubsection{Changes in institutions}

The estimated coefficients reported in table 3 do not provide us with the magnitude of the correlations between the relevant variables, especially when taking into account the opposite effects associated with different intermediate inequality measures. For this reason, we have carried out two exercises, reported in table 4 . In the top part of the table we consider an exogenous variation of $10 \%$ of each institutional measure, other things kept constant. In the bottom part we consider a larger variation of the same variables, corresponding to one standard deviation. ${ }^{21}$ We can compare the effects of a LMI change onto the Gini index and the intermediate inequality (as estimated from 3SLS estimates of table

\footnotetext{
21 These effects are computed by using all the estimated coefficients reported in table 2, irrespective of their statistical significance, otherwise the predicted value would be different from the sample mean.
} 
2) with the overall impact obtained from the reduced form estimated coefficients from table 3. In both cases we consider estimates obtained when excluding Spain from the sample.

\section{Table 4 approximately here}

It is reassuring that most of the signs of the two set of estimates are concordant. Union presence (both union density and wage bargaining coordination) reduces unemployment. Job security in the labour market (measured by the unemployment benefit) also exerts a similar negative impact: the rise in the wage share is more effective in reducing income inequality than the corresponding increase in unemployment. Employment protection is the institution for which we find conflicting results across the two sets of estimates: in the equation system it raises inequality through reduced wage pressure which lowers the wage share (though the impact is small, because it is offset by the interaction effect with the unemployment benefit ${ }^{22}$, while in the reduced form it exhibits a strong negative correlation with overall income inequality. Both the minimum wage and tax wedge show identical signs, but the magnitude of the impact of both variables is higher in the reduced form model.

Union density appears as the institutional variable with the strongest overall negative correlation with income inequality, which is the joint result of a larger wage share and reduced earnings differential. Greater wage coordination, other things constant, is associated with higher inequality and lower unemployment, a situation which is usually perceived as being typical of countries with centralised wage settings (like the Nordic ones). The table highlights the trade-off that emerges between union density, which tends to reduce inequality, and wage bargaining, which tends to increase it. Although the opposite sign of the impact of certain institutions on employment and average wages has already been identified (for example Bertola and oths., 2001), what is novel here is the focus on income inequality. Since institutions often move together - as is the case of union density and wage bargaining coordination - the question of how labour market reforms would impact on inequality becomes difficult to answer. A similar trade-off appears when we consider the unemployment benefit and the tax wedge, which again tend to be correlated (partly due to the fact that high taxes are required in order to finance a generous benefit). These two institutions have the same effect on unemployment, but opposite impacts on inequality, with a higher benefit tending to reduce it and a higher tax to increase it.

\subsubsection{Decomposing country differences}

\footnotetext{
22 Since the simulation is performed by setting the two interacted variables, employment protection and unemployment benefit, separately at their sample means, this neglects the nonlinearity of the interaction, that renders the mean of the interaction different from the means of the constituting variables, which may explain why we get a sign reversal in this case.
} 
Moving one step ahead in the direction of clarifying the relationship between the set of LMIs and income inequality, we explore regional variation in the pattern of these correlations. In fact, the estimation of regional models of income inequality allows us to undertake a number of decomposition exercises. In table 5 we have performed two types of exercises: by reading the table vertically, we obtain what would be income inequality in a particular region had it experienced the institutional values of another region; by reading it horizontally, we have the inequality that one region would have recorded if were to experience the estimated structure of another country. For example, the average of AngloSaxon countries reports an income inequality Gini index of 0.306, which is the joint outcome of regional averages for labour market institutional variables and the reduced form estimated in column 7 of table 3. The same institutional set-up applied to Nordic countries would yield a somewhat higher level of income inequality (0.305), but applied to continental Europe it would result in a dramatic increase in inequality ( 0.572 is roughly the Gini index found in the world's most unequal countries, such as Venezuela or Brazil). If we retain the structure of the Anglo-Saxon economies and we introduce the institutional set-up of other regions, we obtain a reduction in the degree of inequality in the Scandinavian economies, and an increase in inequality in continental Europe). This suggests that the differences in income inequality across world regions are due both to differences in the institutional setup and in the working of the economies.

\section{Table 5 approximately here}

This claim may be made more rigorous if we apply the Oaxaca (1973) decomposition of the differences in income inequality across regions in pair-wise comparisons. Given the reduced form estimates obtained in table 3, we can write it as

$$
\operatorname{Gini}_{i}-\operatorname{Gini}_{j}=\boldsymbol{\beta}_{i}^{\prime} \cdot \mathbf{X}_{i}-\boldsymbol{\beta}_{j}^{\prime} \cdot \mathbf{X}_{j}=\left(\boldsymbol{\beta}_{i}^{\prime}-\boldsymbol{\beta}_{j}^{\prime}\right) \cdot \mathbf{X}_{i}+\boldsymbol{\beta}_{j}^{\prime} \cdot\left(\mathbf{X}_{i}-\mathbf{X}_{j}\right), i \neq j
$$

where the $\boldsymbol{\beta}$ 's denote the vector of (estimated) regression coefficients and the $\mathbf{X}$ 's the (mean) vector of institutional variables. This decomposition is depicted in the figures reported in table 6 , which are to be read as base points of Gini inequality measures. If we are interested in the comparison between market-based economies (Anglo-Saxon) and the social-democratic ones (Scandinavia), according to the definition of Amable (2003), we find that the two regions differ on average by 5.5 base points (from a Gini of 0.306 to a Gini of 0.251), which is almost completely accounted for by differences in institutional measures. However, when we compare Anglo-Saxon economies to continental Europe, the difference of 3.8 base points is the result of large differences in institutions that tend to make Europe less unequal, and large differences in coefficients that work in the opposite directions. A similar result 
appears when we compare Scandinavian countries and continental Europe, although of much smaller magnitude.

\section{Table 6 approximately here}

\subsubsection{Changing institutions}

We have performed a number of simulation exercises to assess the relative importance of the various labour market variables. Such exercises need to be interpreted with care as, first, we are implicitly assuming the exogeneity of institutions, and, second, we are ignoring any policy complementarities that may impede changing a single institution at a time.

To illustrate the process, consider figure 7. Using the estimated coefficients in table 2 we have obtained the predicted values for the Gini coefficient (continuous line). In addition we report the Gini index replacing the country's values of labour market institutions by union density observed in the US (dashed line) and by the US unemployment benefit (dot-dashed line), which are typically lower than their European counterparts (see table A.2 ). The figure illustrates that inequality in the two Scandinavian countries would have been between two and five points higher if one of these institutions had been at US levels. In the case of Norway, both institutional changes have roughly the same impact. In the case of Sweden, which like Norway is characterised by high density rates (due to the so called "Ghent system", where unions run unemployment benefit schemes on behalf of the state), a decline of density rates to the US level would have induced a massive increase in inequality of five Gini points throughout the period, while the impact of unemployment benefit changes is more moderate, as the gap with the US is lower. ${ }^{23}$

\section{Figures 7 and 8 approximately here}

In figure 8 we use the UK union density and unemployment benefit in the prediction for Germany and France. Union density was high in the UK in the early years in our sample, and we see that in the 1970s and 1980s inequality would have been about half a Gini point lower in Germany had it had the same union density as the UK. The difference disappears as union density declined in the UK during Thatcher years. In contrast, the unemployment benefit replacement rate was about seven percentage points higher in Germany, and as a result reducing it to the level paid in the UK would have increased the Gini coefficient in Germany by about one Gini point. The changes in inequality obtained for France are qualitatively similar, although somewhat larger in magnitude, as they result in increase

\footnotetext{
${ }^{23}$ Looking at table A.2, the sample-average replacement rate in US is 0.12 , to be compared with 0.19 of Sweden, 0.22 of UK, 0.26 of Canada and 0.30 of France.
} 
and decreases of about two Gini points. In the case of France, we have not observed the convergence in density rates that occurred between the UK and Germany, and hence density accounts for a large change in inequality in France even in the 1990s.

\section{Policy exercises}

\subsection{Inequality minimizing clusters}

The evidence we have presented can be interpreted as supporting the idea that income inequality in one country/region is shaped by the composition of the labour force (educational attainment, age and gender), as well as by its institutional framework in the labour market. However, we have seen that in some cases strong institutions tend to reduce inequality, as is the case with union density, and in others they tend to raise it, as for the tax wedge. This raises the question of whether we could devise an inequality minimising institutional set-up, represented by strong unions (high membership), protection of employees (high employment protection legislation) and support to unemployed (generous replacement rate). These three aspects can be viewed as complementary, since higher employment protection and improved outside options reinforce unions bargaining power (Bertola 1990). However, they also reduce the demand for union protection, thus pointing to a substitutability between union density, on the one hand, and employment protection and unemployment benefit, on the other (Checchi and Lucifora 2002). What is relevant here is that these three measures are negatively correlated with income inequality. In addition, when unions are strong, minimum wage legislation is less necessary, and can also become counterproductive if it triggers a wage spiral as high-wage workers try to maintain a given wage differential. A lower tax wedge may contribute to reduce income inequality through its positive impact on employment. Lastly, a low degree of wage bargaining coordination would be preferable, because it would allow for significant wage pressure at the bottom of the wage distribution that would tend to raise the wage share and reduce the decile ratio.

The problem with this policy recommendation is that, as is well-known, institutions tend to be clustered, with countries with high values of a particular institution also having high values of certain others. As a result, it may not be possible for a policy maker to set independently each of them. In order to investigate the potential clustering of institutional variables we have resorted to factor analysis (principal component method). In table 7 we show that two factors are extracted, accounting for $2 / 3$ of total variance. When applying the (orthogonal varimax) rotation, we observe that the first factor mostly correlates with union density, coordination of wage bargaining and minimum wage, while the second factor attracts the positive association of unemployment benefit, employment protection and the tax wedge. The first group of institutions concerns the process of wage setting, and with some imagination 
we can label the first factor as "wage setting". The other group of measures describes the degree of job security and its financing; for this reason we label it as "employment security".

\section{Table 7 and Figure 9 approximately here}

Since each country/year observation is associated with a specific value on each extracted factor, in the same table we show that North America is the poorest region in terms of institutional set-up, followed by the other Anglo-Saxons countries. At the other extreme, the Nordic countries have the strongest institutional framework with respect to wage bargaining, while continental Europe records the highest values for employment security. The average position for each country is reported in figure 9. It is interesting to note that European countries like France and Spain exhibit a level of bargaining institutions comparable to the North American one, though accompanied by a higher level of employment security. Conversely, other European countries, such as Austria and Norway, are characterised by strong wage bargaining institutions, although not accompanied by employment security.

We can now assess the correlation of strong "wage setting" institution and high "employment security" with inequality, reported in the bottom panel of table 7. In both cases, the correlation between the institutional clusters and the Gini index is negative and highly significant. This indicates that in both cases strong institutions are associated with a less dispersed distribution of income, implying that the positive correlations obtained in the regressions, most notably that with the tax wedge, are offset by the impact of other institutions.

\subsection{Institutions and the trade-off between inequality and unemployment}

It is a common perception that economies with strong labour market institutions are characterized by low inequality and high unemployment, while those with weaker institutions experience low unemployment rates at the cost of a more unequal distribution of income. Our estimates in table 2 indicate that there are two mechanisms at work. First, the equation for Gini in column 1 implies a positive direct correlation between unemployment and inequality. Second, there are two other indirect mechanisms in operation. A higher unemployment benefit increases the rate of unemployment, but also the labour share which tends to reduce the Gini index. Similarly, greater coordination of wage bargaining reduces the unemployment rate but also the labour share. As a result, it is unclear what the relationship between inequality and unemployment is.

The model estimated in table 2 allows us explore the possible trade-off between these two variables. Consider the effect of wage bargaining coordination. Less coordination would have two effects. First, it would increase the unemployment rate, which in turn would increase income inequality; 
second, it would reduce the decile ratio and increase the wage share, both of which would reduce inequality. The coefficients reported in table 2 imply that a reduction in wage coordination leading to an increase of one percentage point of the unemployment rate would result in a reduction of inequality of one Gini point. A similar exercise can be done for the unemployment benefit, in which case for an increase of one percentage point in unemployment induced by a higher benefit, inequality would fall by 0.96 Gini points. These trade-offs are depicted in figure 10 .

\section{Figures 10 and 11 approximately here}

In order to further examine this trade-off we consider the impact on inequality and unemployment of imposing common labour market institutions. For this exercise we select the 12 countries in our sample that were members of the European Union prior to the recent enlargement. Out of the various institutional measures that we have used, some, such as the minimum wage, can be legislated while others, for example union membership, cannot. Hence we suppose that the common policy consists of imposing in all 12 countries the same values for the four institutions that can be legislated, namely the unemployment benefit rate, the degree of employment protection, the minimum wage (also extended to countries that do not have it), and the tax wedge. The common institutions are set equal to the average of those observed in these 12 countries in the latest year for which we have data on inequality (i.e. at some point between 1999 and 2004). ${ }^{24}$ Countries still differ in the other institutions (union density rate and coordination of wage bargaining) as well as in the level of education, demographic characteristics, openness, and investment rate.

Figure 10 presents the results. It plots the Gini coefficients of total income against the unemployment rates. Each arrow represents a country, with the starting point being the unemployment/inequality pair under the observed country institutions, and the end point the level of unemployment/inequality under the common labour standard. If institutions do indeed create a tradeoff between unemployment and inequality, countries should be moving either South-East, if their institutions are weakened, or North-West if the common labour standard implies more stringent LMIs. We can see that Denmark, the Netherlands and Spain fit this pattern, and would all experience a reduction in unemployment at the expense of a more unequal distribution of income. The outcome for the two largest continental economies is rather surprising. Germany shifts to the North-West, i.e. to higher unemployment and lower inequality, while in France inequality is unchanged but unemployment falls. A number of countries find themselves in a win-win situation: Belgium, Finland, Italy, and Sweden all experience reductions in both the degree of inequality and the unemployment rate. The losers are

\footnotetext{
${ }^{24}$ Since some countries do not have a minimum wage, when we calculate the common minimum wage we use the mean value for those countries that do have it.
} 
Ireland and the UK (and to a much smaller extent also Austria) since they all witness a major increase in unemployment with only a tiny reduction in the Gini coefficient. To understand this, look again at figure 9. The main difference between Ireland and the UK, on the one hand, and the rest of the EU members, on the other, is the degree of employment security. The common labour standard would hence imply that these two countries experience an increase in aspects related to employment security, which raise unemployment sharply, and little change in wage setting institutions which are the first factor responsible for reductions in inequality.

\section{Policy implications and concluding remarks}

In this paper we have provided a unified framework to examine the impact of labour market institutions on labour market outcomes, and through them on income inequality. Our results indicate that labour market institutions exhibit significant correlations with the distribution of income across countries and over time. Stronger institutions are correlated with lower inequality, with the notable exception of the tax wedge that exhibits a positive correlation with the Gini coefficient. Within this framework, we have tried to identify a set of inequality minimizing institutions. Our analysis has delineated two clusters of institutions. The first consists of the "wage setting" institutions, while the second group of measures describes the degree of job security and out-of-job income, that is, is a measure of "employment security". Under the hypothesis that our results capture, to some extent, a causal relationship, strengthening either of these two elements would result in lower income inequality.

Our clustering of institutional measures allows for a description of regional patterns in institutions. North America is the poorest region in terms of institutional set-up, followed by the other Anglo-Saxons countries. At the other extreme, the Nordic countries have the strongest institutional framework with respect to wage bargaining, while continental Europe records the highest values for employment security. The estimates we have obtained indicate that strong wage setting institutions are more effective at reducing inequality than the alternative policy of providing employment security implemented in continental Europe.

These results have important implications for the recent discussions taking place in the EU on the implementation of common labour market reforms in order to increase employment. A central element of the so-called "flexicurity" agreements that the EU proposes is a reduction in employment protection legislation. A consequence of such policy is likely to be a substantial increase in income inequality. However, our findings indicate that strong wage setting institutions are more effective at reducing inequality than employment protection. This suggests that a possible strategy would be to shift institutions in the Anglo-Saxon and large continental countries, with the aim of encouraging employment through a reduction in employment protection, while offsetting the distributional 
implications of this policy by fostering a wage determination system that increases the share of wages in national income.

European leaders have a clear desire to have a common institutional setup for labour markets across the Union; see Commission of the European Communities (2007). A crucial question in this debate is whose institutions should be adopted. We have performed an exercise in which the 12 (preenlargement) EU members adopt a common labour standard given by the average value across these countries of those policies that can be legislated: EPL, the tax wedge, the minimum wage and the unemployment benefit. We can then quantify the extent to which institutional changes aimed at reducing unemployment will tend to increase income inequality. Out of the 12 economies, four countries were better off - i.e. inequality and unemployment both decreased - , three countries were worse off along the two dimensions, and the other five moved their position along the inequalityunemployment trade-off. We view this as a rather unsatisfactory outcome, since only a third of the economies can be said to benefit from the policy. The reason for this outcome is, in our view, the fact that three out of the four policies - unemployment benefit, employment protection and the tax wedge - concern employment security, which is a less effective mechanism for reducing inequality while it has a strong effect on unemployment. Our estimates suggest that a more efficient strategy would be to promote strong wage-setting institutions, as exist in the Scandinavian economies, which both have a weaker effect on unemployment and result in a stronger reduction in inequality.

There is a caveat in this recommendation, as it is much easier for policy-makers to legislate employment relations or the benefit replacement rate than it is to increase union membership or the degree of wage coordination. Understanding the economic and institutional conditions under which strong unions are likely to appear is hence a crucial question.

Our results also shed some light on the debate over whether strong labour market institutions are efficient. One side of the debate maintains that these institutions help agents to cope with uncertainty by reducing employment and income risks, and hence not only increase their welfare but may also encourage investments in skills and human capital. The other side argues that these institutions are mainly the channels through which certain economic groups engage in rent-seeking behaviour that allows them to boost their share in national income. The finding that stronger institutions are associated with less inequality indicates that the redistributive effect of institutions is to increase the income share of those at the bottom of the distribution (more than the share of those at the top of the distribution, since the wage differential shrinks under strong bargaining institutions). Hence even if they allow, to some extent, for rent-seeking behaviour the end result is, in our view, a desirable reduction in the dispersion of income.

Lastly, it is important to emphasize that, as is generally the case, our measure of inequality is a snap-shot of the distribution of income at a particular point in time. This implies that we are potentially 
ignoring all aspects related to the dynamics of individual incomes which are potentially affected by labour market institutions. For example, weak institutions are likely to increase job turnover and the volatility of earnings. Then, measured inequality can be high at a point in time simply because individuals with the same permanent income are experiencing different shocks. If agents know their permanent income and smooth accordingly their consumption, then consumption inequality may be used as a proxy for inequality in permanent incomes. Examining the relationship between consumption inequality and labour market institutions is an important but still unanswered question. 


\section{Appendix I: Data source and descriptive statistics}

\section{Factor incomes}

Data on incomes are obtained from the Luxemburg Income Study (www.lisproject.org, results obtained between 1/12/2007 and 1/03/2008). In LIS there are two files per country/year, a household file and a personal file. Only the former contains information on capital income, hence we have focused on household income.

In the LIS household file there is an aggregate variable for labour income (V1/V1NET = gross/net wages and salaries) to which we add payroll taxes (V2 $=$ mandatory employer contributions $+\mathrm{V} 3=$ non mandatory employer contributions) and in kind earnings (V6= In-kind income as a substitute or complement for cash wages - includes, for example, the value of company cars, meals, housing, electricity, medical expenses, child care etc. paid or partly paid by the employer) in order to get LABOUR INCOME.

Within the same household file there is an aggregate variable for capital income $(\mathrm{V} 8=$ cash property income: Cash interest, rent, dividends, annuities, private individual pensions, royalties, etc. Excludes capital gains, lottery winnings, inheritances, insurance settlements, and all other forms of one-off lump sum payments) to which we sum self-employment income (V4=farm self-employment income $+\mathrm{V} 5=$ non-farm self-employment income: Profit/loss from unincorporated enterprises; the income is recorded gross of social insurance contributions, but net of expenses), payroll taxes (V7=mandatory contribution for self-employment: mandatory social insurance contributions paid by the self-employed: social security, medical insurance, unemployment, etc.) and non-cash property income (V9= estimates of imputed rental income from own home.), in order to get CAPITAL INCOME.

Finally, we consider BENEFIT INCOME (variable V21 = Full or partial unemployment insurance benefits, vocational training benefits, relocation benefits, and other benefits from unemployment insurance). The following definitions are then adopted:

FACTOR INCOME $=$ LABOUR INCOME + CAPITAL INCOME, and

TOTAL INCOME = LABOUR INCOME + CAPITAL INCOME + BENEFIT INCOME.

NET DISPOSABLE INCOME = LABOUR INCOME + CAPITAL INCOME + BENEFIT INCOME + OTHER

TRANSFERS - MANDATORY PAYROLL TAXES - INCOME TAXES.

Each type of income is rescaled at per capita values using an equivalence scale given by the square root of the number of family members. All missing or negative values are set equal to zero. ${ }^{25}$

The WAGE SHARE is then computed at the household level from the following definition:

WAGE SHARE=LABOUR INCOME/(LABOUR INCOME + CAPITAL INCOME),

and then averaged across households. The DECILE RATIOS are computed across households with positive labour income. The GINI INEQUALITY INDEX is also computed across households' factor incomes and total incomes. These measures are weighted using the original sample weights available in LIS multiplied by the number of earners in the household. ${ }^{26}$

Descriptive statistics are reported in table A.1.

\footnotetext{
25 Since we include self-employment incomes (which record negative values in a fraction of the population), this leads to an underestimate of the inequality measures produced by our data.

${ }^{26}$ LIS project suggests using internal weights, which we used at the beginning of our analysis. But since household incomes are rescaled using equivalence scale, each household becomes equivalent to a representative individual with labour and capital incomes equivalent to the (equivalised) mean value in the family. But families still differ in terms of how many earners are in the family. Thus we decided to use as weights the product of the original sample weights in the survey $\times$ the number of earners in the family. This procedure gets closer to being representative of the working population in the country.
} 


\section{Other variables}

\section{Coordination of wage bargaining}

Indicators of the degree of centralisation and/or coordination of the wage bargaining processes, which take value 1 for decentralised and uncoordinated processes, and up to 5 for high degrees of centralisation/co-ordination, respectively. Source: Bassanini and Duval (2006), which in turn is based on reclassification of original data proposed in OECD, Employment Outlook 2004.

\section{Education}

This measure is computed from LIS-Household file, as the proportion of household heads (unweighed) with some tertiary education (ISCED $5 \mathrm{a}$ and $5 \mathrm{~b}$ )

\section{Employment Protection Legislation (EPL)}

OECD summary indicator of the stringency of Employment Protection Legislation, overall index. Source: OECD, Employment Outlook 2004. It has been backward projected before 1982 using the EPL measure taken from Nickell and oths. (2005), which in turn was based on Blanchard and Wolfers (2000).

\section{Female share in employment}

It is computed as the share of female civilian employment from Comparative Welfare States Data Set. When absent, it has been replaced by analogous value obtained from Bassanini and Duval (2006)

\section{Gross investment in gross domestic product}

Ratio of gross investment to Gross Domestic Product, measured at PPP. Source: Penn World Tables 6.2 .

\section{Minimum wage}

Ratio of statutory minimum wage to median wage, in percentage. Source: OECD Minimum Wages Database (downloadable). For countries where minimum wage provision is absent we have considered predicting a value based on union coverage, but this information is not available for few countries (Ireland, Greece) or only available in recent years. For this reason we have preferred to impose a unitary value when minimum wage is absent, except for Ireland and UK, where it was introduced in 2000 ; in such a case it has been replaced by country sample average in order not to distort the estimated coefficient.

\section{Social security transfer}

Social security transfers as a percentage of GDP. Consists of benefits for sickness, old-age, family allowances, etc., social assistance grants and welfare. Source: OECD, Historical Statistics, various years (2001), Table 6.3.

\section{Tax wedge}

The measure of the tax wedge used in the text is from Bassanini and Duval (2006), and is derived from OECD tax models and therefore only captures labour taxes (social security contributions and income taxes), but not consumption taxes. It is defined as the wedge between the labour cost to the employer and the corresponding net take-home pay of the employee for a single-earner couple with two children earning $100 \%$ of APW (average productive wage) earnings. The tax wedge expresses the sum of personal income tax and all social security contributions as a percentage of total labour cost. It has been backward projected before 1982 using the tax wedge measure taken from Nickell and oths. (2005).

\section{Trade openness}

Current-prices economic openness, computed ad (exports + imports) as percentage of current GDP. Source: Comparative Welfare States Data Set (Assembled by Evelyne Huber, Charles Ragin, and John 
D. Stephens - December 1997 - Updated by David Brady, Jason Beckfield, and John Stephens - April 2004 - from http://www.lisproject.org/publications/welfaredata/welfareaccess.htm)

\section{Union Density}

Trade union density rate, i.e. the share of workers affiliated to a trade union, in percentage. Source: OECD, Employment Outlook 2004.

\section{Unemployment benefit}

The OECD summary measure is defined as the average of the gross unemployment benefit replacement rates for two earnings levels, three family situations and three durations of unemployment. Since the data is originally produced every two years, the missing values have been replaced by the average of two contiguous values. Source: OECD 2007, Benefit and wages, Paris.

\section{Unemployment rate}

The (aggregate) unemployment rate is taken from Nickell et al (2005).

Descriptive statistics for labour market institutions are reported in table A.2 . 


\section{References}

Acemoglu, D. 2003. Cross-country Inequality, The Economic Journal, 113, pp. F121-F149.

Agell, Jonas, and Kjell Erik Lommerud 1993. Egalitarianism and Growth. Scandinavian Journal of Economics 95: 559-579.

Alderson, A. and F. Nielsen. 2002. Globalisation and the great U-turn: income inequality trends in 16 OECD countries. American Journal of Sociology 107: 1244-1299.

Amable, Bruno. 2003. The diversity of modern capitalism. Oxford University Press

Antras, P. 2004. Is the U.S. Aggregate Production Function Cobb-Douglas? New Estimates of the Elasticity of Substitution, Contributions to Macroeconomics, 4 (1).

Atkinson, A.B. 1997. Bringing the Income Distribution in from the Cold, The Economic Journal, 107(441): 297-321.

Atkinson, A.B. 2007. Distribution and growth in Europe - the empirical picture: a long-run view of the distribution of income, mimeo.

Atkinson, A.B. and A. Brandolini. 2001. Promise and Pitfalls in the Use of Secondary Data-Sets: Income Inequality in OECD Countries as a Case Study, Journal of Economic Literature, 39(3): 771 99.

Atkinson, A.B. and A. Brandolini. 2003. The Panel-of-Countries approach to explaining income inequality: an interdisciplinary agenda. Mimeo

Autor, A.H., W.R. Kerr and A.D. Kugler. 2007. Does Employment Protection Reduce Productivity? Evidence from US states, The Economic Journal 117: F189-F217.

Baker, D., A. Glyn, D. Howell and J. Schmitt 2004, Labor Market Institutions and Unemployment : A Critical Assessment of the Cross-Country Evidence, in D.Howell (ed.), Fighting Unemployment: The Limits of Free Market Orthodoxy, Oxford, Oxford University Press.

Barro, R.J. 2000. Inequality and Growth in a Panel of Countries, Journal of Economic Growth, 5: 5-32.

Bassanini, A. and R. Duval. 2006. Employment patterns in OECD countries: reassessing the role of policies and institutions. OECD Economics Department working papers no. 486

Belot, M. and J. Van Ours 2004. Does the Recent Success of Some OECD Countries in Lowering their Unemployment Rates Lie in the Clever Design of their Labour Market Reform?., Oxford Economic Papers, 56(4): 621-642.

Bentolila S. and G. Saint-Paul, 2003. Explaining Movements in the Labor Share, Contributions to Macroeconomics 3(1), article 9.

Bertola, G. 1990. Job security, employment and wages. European Economic Review 6, 851-886.

Bertola, G. F. Blau, and L. Kahn, 2002. Comparative Analysis of Labor Market Outcomes: Lessons for the US from International Long-Run Evidence, in A. Krueger and R. Solow (eds.), The Roaring Nineties: Can Full Employment be Sustained?, Russell Sage and Century Foundations, pp. 159-218.

Blanchard, O. 1997. The Medium Run. Brookings Papers on Economic Activity, 2: 89-158.

Blanchard, O. and Wolfers, J. 2000. The Role of Shocks and Institutions in the Rise of European Unemployment: the Aggregate Evidence. The Economic Journal, 110: C1-C33.

Blanchard, O., and J. Tirole. 2004. The optimal design of unemployment insurance and employment protection. A first pass. Massachusetts Institute of Technology, Department of Economics, Working Paper No. 04-15.

Bourguignon, F. and Morrisson, C. 1998. Inequality and development and: the role of dualism, Journal of Development Economics, 57 0: 233-57.

Brandolini, A. and T. Smeeding. 2007. Inequality Patterns in Western-Type Democracies: CrossCountry Difference and Time Changes, ChilD discussion paper 08/2007.

Calmfors, L., and J. Driffill. (1988). Centralisation of wage bargaining and macroeconomic performance. Economic Policy 6: 13-61.

Card, D., T. Lemieux and W.C. Riddell. 2004. Unions and Wage Inequality Journal of Labor Research, Vol. 25(4), pp. 519-562.

Checchi, D. and C. García Peñalosa. 2005. Labour shares and the personal distribution of income in the OECD. IZA Discussion Paper No. 1681/2005 
Checchi, D. and C. García Peñalosa. 2008. Labour Market Institutions and Income Inequality. LIS working paper no. 470.

Checchi, D. and C. Lucifora. 2002. Unions and labour market institutions in Europe. Economic Policy 17(2): 362-401.

Commission of the European Communities. 2007. Towards Common Principles of Flexicurity: More and better jobs through flexibility and security. European Commission.

Deaton, A., 2005. Measuring Poverty in a Growing World (or Measuring Growth in a Poor World). The Review of Economics and Statistics, 87, 1619.

Gollin D., 2002. Getting Income Shares Right. Journal of Political Economy, vol. 110, no. 2, 458-474.

Gottschalk, P. and S. Danziger, 2005. Inequality of Wage Rates, Earnings and Family Income in the United States, 1975-2002, Review of Income and Wealth, 51: 231-254.

Gottschalk, P., 1997. Policy Changes and Growing Earnings Inequality in the US and Six Other OECD Countries, in P. Gottschalk, B. Gustafsson and E. Palmer (eds.), Changing Patterns in the Distribution of Economic Welfare. An International Perspective, Cambridge, Cambridge University Press.

Hall, P. and D. Soskice. 2001. Varieties of capitalism: the institutional foundations of comparative advantage. Oxford University Press

Katz L.F. and Murphy, K.M., 1992. Changes in Relative Wages, 1963-1987: Supply and Demand Factors, Quarterly Journal of Economics, vol. 107(1), pp. 35-78

Koeninger, W., M. Leonardi and L. Nunziata. 2007. Labour market institutions and wage inequality, Industrial \& Labor Relations Review, 60(3), pp. 340-356.

Lee, D.S. 1999. Wage Inequality in the United States during the 1980s: Rising Dispersion or Falling Minimum Wage? Quarterly Journal of Economics, 112: 977-1023.

Li, H., L. Squire and H-F. Zou. 1998. "Explaining International and Intertemporal Variations in Income Inequality", The Economic Journal 108: 26-43.

Li, H., L. Squire and H-F. Zou. 1998. Explaining International and Intertemporal Variations in Income Inequality, The Economic Journal 108: 26-43.

Mahler, V. A. (2004), Economic Globalization, Domestic Politics and Income Inequality in the Developed Countries: A Cross-National Study, Comparative Political Studies, 37, 1025-1053.

Nickell, S. 1997.Unemployment and Labor Market Rigidities: Europe versus North America. The Journal of Economic Perspectives, 11(3): 55-74.

Nickell, S. and L. Nunziata. 2001. Labour market institutions database

Nickell, S., L. Nunziata and W. Ochel. 2005. Unemployment in the OECD Since the 1960s: What Do We Know?. The Economic Journal. 115(500): 1-27.

Oaxaca, R. 1973. Male-female Wage Differentials in Urban Labor Markets, International Economic Review 14(3): 693-709.

OECD 2002. Benefits and wages - OECD indicators. Paris.

Piketty, T. 2003. Income inequality in France, 1901-1998, Journal of Political Economy, 111: 1004-1042.

Saint-Paul, Gilles. 2000. The political economy of labour market institutions. Oxford University Press.

Summers, R. and A. Heston. 1991. The Penn World Table(Mark 5): An expanded set of international comparisons,1950-1988, Quarterly Journal of Economics 106(2): 327-368.

Visser, J. 2007. Database on Institutional Characteristics of Trade Unions, Wage Setting, State Intervention and Social Pacts (ICTWSS), NEWGOV project, financed under the EU FP7 research framework, on Distributive Politics, Learning and Reform: National Social Pacts. 
Table 1- Determinants income inequality - OLS regressions - various income definitions

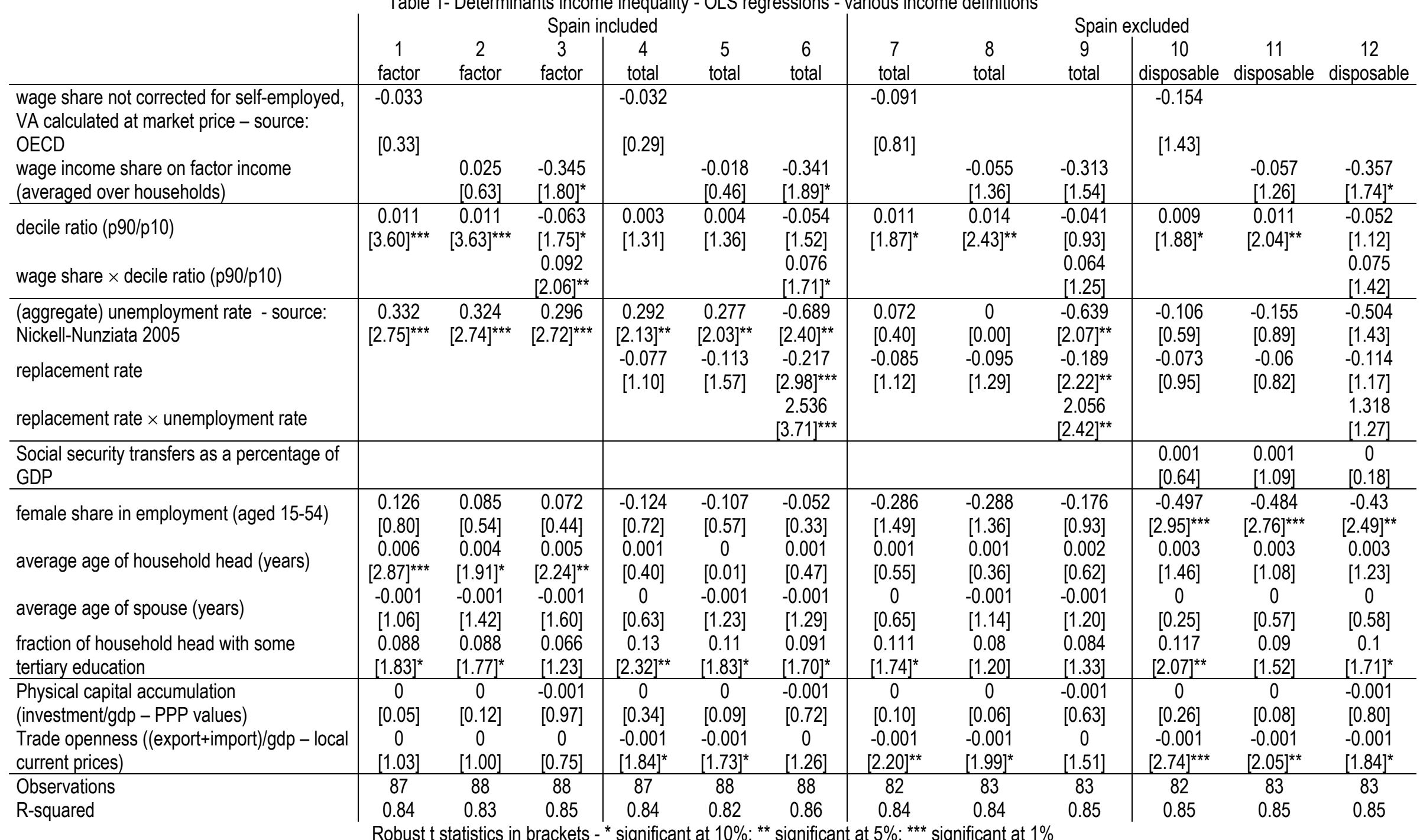

Controls for countries, decades and income definitions included - Data for social transfer are not available for Spain 
Table 2 - Determinants of total income inequality - 3SLS regressions - Total income

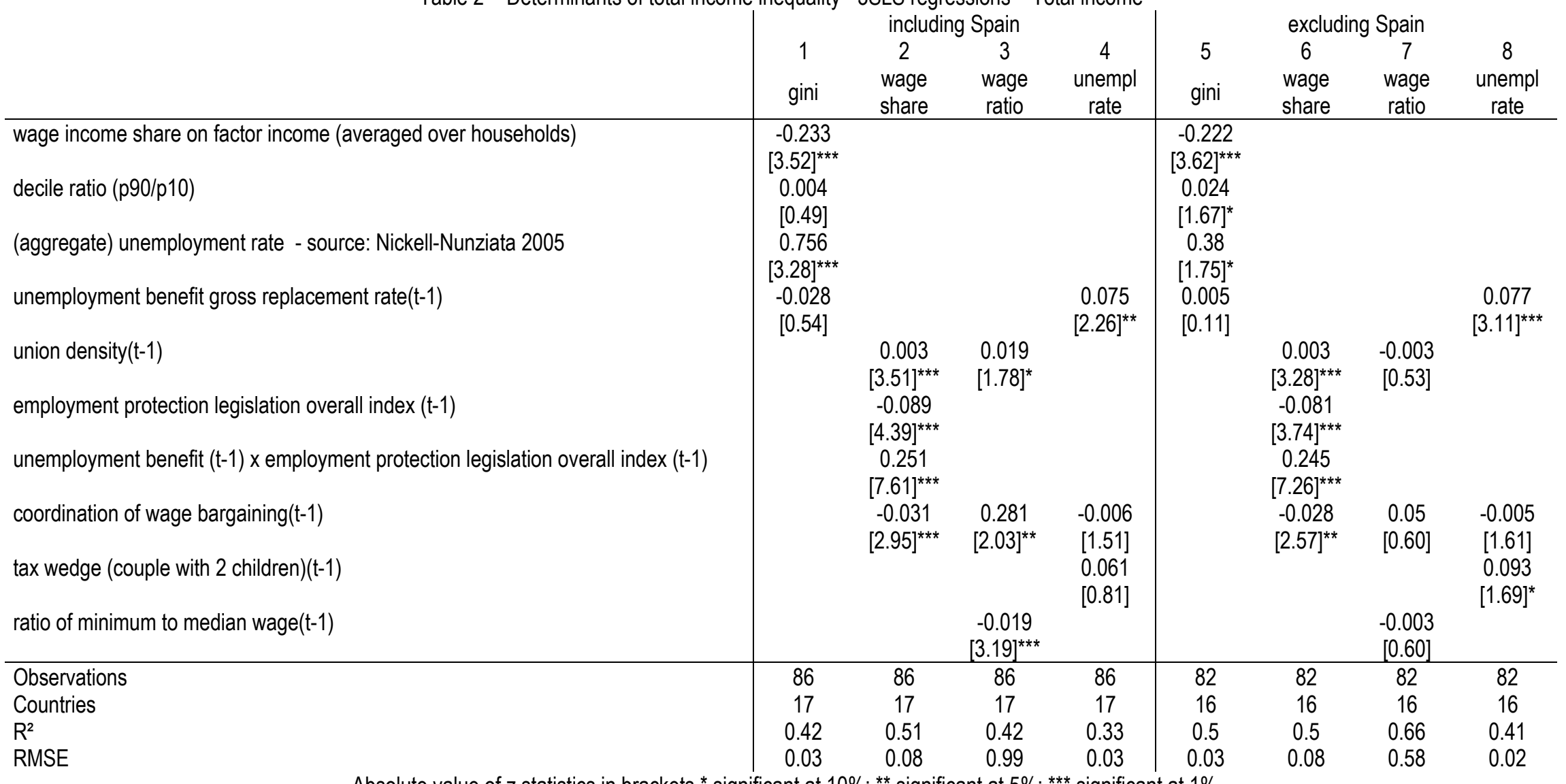

Absolute value of $z$ statistics in brackets * significant at $10 \%$; ${ }^{* *}$ significant at $5 \%$; ${ }^{* *}$ significant at $1 \%$

Controls for regions, decades, education, gender, age, investment (unemployment equation) and trade openness (decile ratio equation) included. 


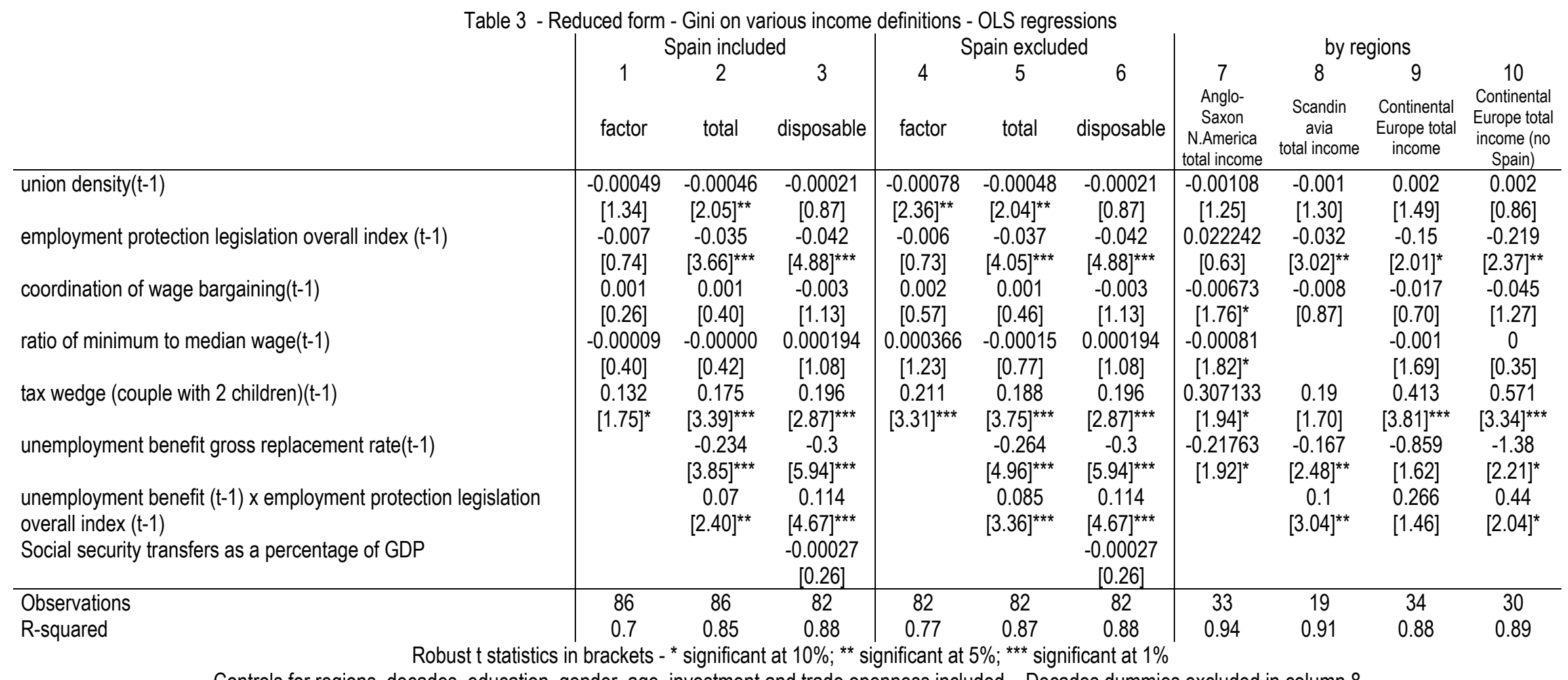

Controls for regions, decades, education, gender, age, investment and trade openness included - Decades dummies excluded in column 8 
Table 4 - The impact of changes in labour market institutions (using the model estimated in table 2 (excluding Spain) and column 5 in table 3)

\begin{tabular}{|c|c|c|c|c|c|}
\hline & $\begin{array}{c}\text { Gini index } \\
\text { total income }\end{array}$ & $\begin{array}{l}\text { wage } \\
\text { share }\end{array}$ & $\begin{array}{c}\text { decile ratio } \\
\text { p90/p10 }\end{array}$ & $\begin{array}{l}\text { unemploym } \\
\text { rate }\end{array}$ & \multirow{4}{*}{$\begin{array}{l}\text { Gini index } \\
\text { total } \\
\text { income } \\
\text { (OLS } \\
\text { reduced } \\
\text { form) } \\
\end{array}$} \\
\hline sample means & 0.279 & 0.789 & 3.953 & 0.068 & \\
\hline \multirow[t]{2}{*}{ sample standard deviation } & 0.037 & 0.117 & 1.006 & 0.031 & \\
\hline & \multicolumn{4}{|c|}{ 3SLS system estimation } & \\
\hline \multicolumn{6}{|c|}{ the effect of $10 \%$ increase in institutional variables } \\
\hline $\begin{array}{l}\text { unemployment benefit gross replacement rate } \\
\text { union density } \\
\text { employment protection legislation overall index } \\
\text { coordination of wage bargaining } \\
\text { ratio of minimum to median wage } \\
\text { tax wedge (couple with } 2 \text { children) }\end{array}$ & $\begin{array}{c}-0.84 \% \\
-1.08 \% \\
0.08 \% \\
0.59 \% \\
-0.17 \% \\
0.37 \% \\
\end{array}$ & $\begin{array}{c}1.87 \% \\
1.51 \% \\
-0.14 \% \\
-1.09 \%\end{array}$ & $\begin{array}{r}0.39 \% \\
-0.47 \%\end{array}$ & $\begin{array}{c}-2.36 \% \\
4.10 \% \\
\end{array}$ & $\begin{array}{l}-0.83 \% \\
-0.72 \% \\
-0.77 \% \\
0.11 \% \\
-0.39 \% \\
2.01 \% \\
\end{array}$ \\
\hline \multicolumn{6}{|c|}{ the effect of 1 standard deviation increase in terms of standard deviation of the dependent variable } \\
\hline $\begin{array}{l}\text { unemployment benefit gross replacement rate } \\
\text { union density } \\
\text { employment protection legislation overall index } \\
\text { coordination of wage bargaining } \\
\text { ratio of minimum to median wage } \\
\text { tax wedge (couple with } 2 \text { children) }\end{array}$ & $\begin{array}{c}-19.45 \% \\
-38.99 \% \\
15.17 \% \\
20.15 \% \\
-4.59 \% \\
8.75 \% \\
\end{array}$ & $\begin{array}{l}44.81 \% \\
48.81 \% \\
-21.56 \% \\
-32.56 \%\end{array}$ & $\begin{array}{c}0.0678555 \\
-6.76 \%\end{array}$ & $-22.81 \%$ & $\begin{array}{c}-95.87 \% \\
-26.21 \% \\
-114.92 \% \\
3.73 \% \\
-11.01 \% \\
46.99 \%\end{array}$ \\
\hline
\end{tabular}


Table 5 -Gini index on total incomes computed using labour market institutions

under different regional impacts

(using the model estimated in table 3-columns 7-8-10)

including constants, education, age, gender, trade openness and investment

\begin{tabular}{l|ccc}
\begin{tabular}{l|c} 
coefficients $\rightarrow$ \\
$\downarrow$ labour market institutions variables
\end{tabular} & $\begin{array}{c}\text { Anglo-Saxons } \\
\text { (incl.North America) }\end{array}$ & Scandinavia & Continental Europe \\
\hline Anglo-Saxons (incl.North America) & 0.306 & 0.304 & 0.601 \\
Scandinavia & 0.191 & 0.251 & 0.331 \\
Continental Europe & 0.335 & 0.288 & 0.268
\end{tabular}

excluding education, age, gender, trade openness and investment

\begin{tabular}{l|ccc}
$\begin{array}{l}\text { coefficients } \rightarrow \\
\downarrow \text { labour market institutions variables }\end{array}$ & $\begin{array}{c}\text { Anglo-Saxons } \\
\text { (incl.North America) }\end{array}$ & Scandinavia & Continental Europe \\
\hline Anglo-Saxons (incl.North America) & 0.306 & 0.305 & 0.572 \\
Scandinavia & 0.260 & 0.251 & 0.317 \\
Continental Europe & 0.346 & 0.307 & 0.268
\end{tabular}

Table 6 - Oaxaca decomposition for Gini index on total incomes

(using the model estimated in table 3 - columns 7-8-10)

Anglo-Saxons - Continental Europe Continental Europe - Scandinavia Anglo-Saxons - Scandinavia

$\begin{array}{ccc}\text { Gini }_{i}-\text { Gini }_{j} & \left(\boldsymbol{\beta}_{i}^{\prime}-\boldsymbol{\beta}_{j}^{\prime}\right) \cdot \mathbf{X}_{i} & \boldsymbol{\beta}_{j}^{\prime} \cdot\left(\mathbf{X}_{i}-\mathbf{X}_{j}\right) \\ 0.038 & -0.266 & 0.304 \\ 0.017 & -0.039 & 0.056 \\ 0.055 & 0.001 & 0.054\end{array}$


Table 7 - Factor extraction from labour market institutions variables

\begin{tabular}{|c|c|c|c|c|c|}
\hline \multicolumn{6}{|c|}{ factor extraction - principal components method } \\
\hline & factor lo & otation) & \multicolumn{2}{|c|}{ factor loading (after rotation) } & uniqueness \\
\hline union density & 0.605 & -0.524 & 0.798 & 0.055 & 0.360 \\
\hline unemployment benefit gross replacement rate & 0.491 & 0.362 & 0.093 & 0.603 & 0.628 \\
\hline employment protection legislation overall index & 0.769 & 0.449 & 0.229 & 0.861 & 0.206 \\
\hline coordination of wage bargaining & 0.745 & -0.333 & 0.763 & 0.289 & 0.334 \\
\hline ratio of minimum to median wage & 0.715 & -0.474 & 0.841 & 0.168 & 0.265 \\
\hline tax wedge (couple with 2 children) & 0.700 & 0.543 & 0.114 & 0.878 & 0.215 \\
\hline Variance explained & 0.4590 & 0.2061 & 0.3334 & 0.3317 & \\
\hline
\end{tabular}

Note: factor extracted from 525 observations concerning 17 countries

\begin{tabular}{|c|c|c|}
\hline \multicolumn{3}{|c|}{$\begin{array}{l}\text { correlation with regional dummies } \\
\text { factor load }\end{array}$} \\
\hline region==Anglo-Saxon & $\begin{array}{c}-0.119 \\
{[2.09]^{* *}}\end{array}$ & $\begin{array}{c}-1.054 \\
{[32.95]^{\star * *}}\end{array}$ \\
\hline region==Scandinavia & $\begin{array}{c}1.193 \\
{[62.19]^{* * *}}\end{array}$ & $\begin{array}{c}0.292 \\
{[7.19]^{\star * *}}\end{array}$ \\
\hline region==continental Europe & $\begin{array}{c}1.193 \\
{[62.19]^{\star * *}}\end{array}$ & $\begin{array}{c}0.292 \\
{[7.19]^{\star * *}}\end{array}$ \\
\hline region==North-America & $\begin{array}{c}-0.272 \\
{[4.53]^{\star * *}}\end{array}$ & $\begin{array}{c}0.809 \\
{[17.32]^{\star \star *}}\end{array}$ \\
\hline $\begin{array}{l}\text { Observations } \\
\text { R-squared }\end{array}$ & $\begin{array}{l}525 \\
0.38\end{array}$ & $\begin{array}{l}525 \\
0.54\end{array}$ \\
\hline
\end{tabular}

Robust t statistics in brackets

* significant at $10 \%$; ** significant at $5 \%$; *** significant at $1 \%$

\begin{tabular}{l|cc|} 
& \begin{tabular}{c}
\multicolumn{3}{c}{ correlation with relevant variables } \\
factor loading (after rotation) \\
factor 1
\end{tabular} & $\begin{array}{c}\text { factor2 } \\
\text { "wage setting" }\end{array}$ \\
& -0.02 & -0.013 \\
Correlation with Gini index on total income & {$[7.09]^{* * *}$} & {$[4.16]^{* *}$} \\
\hline Observations & \multicolumn{2}{|c|}{85} \\
R-squared & \multicolumn{2}{|c|}{0.48} \\
\hline
\end{tabular}


Figure 1 - Income inequality: Gini index on gross household income

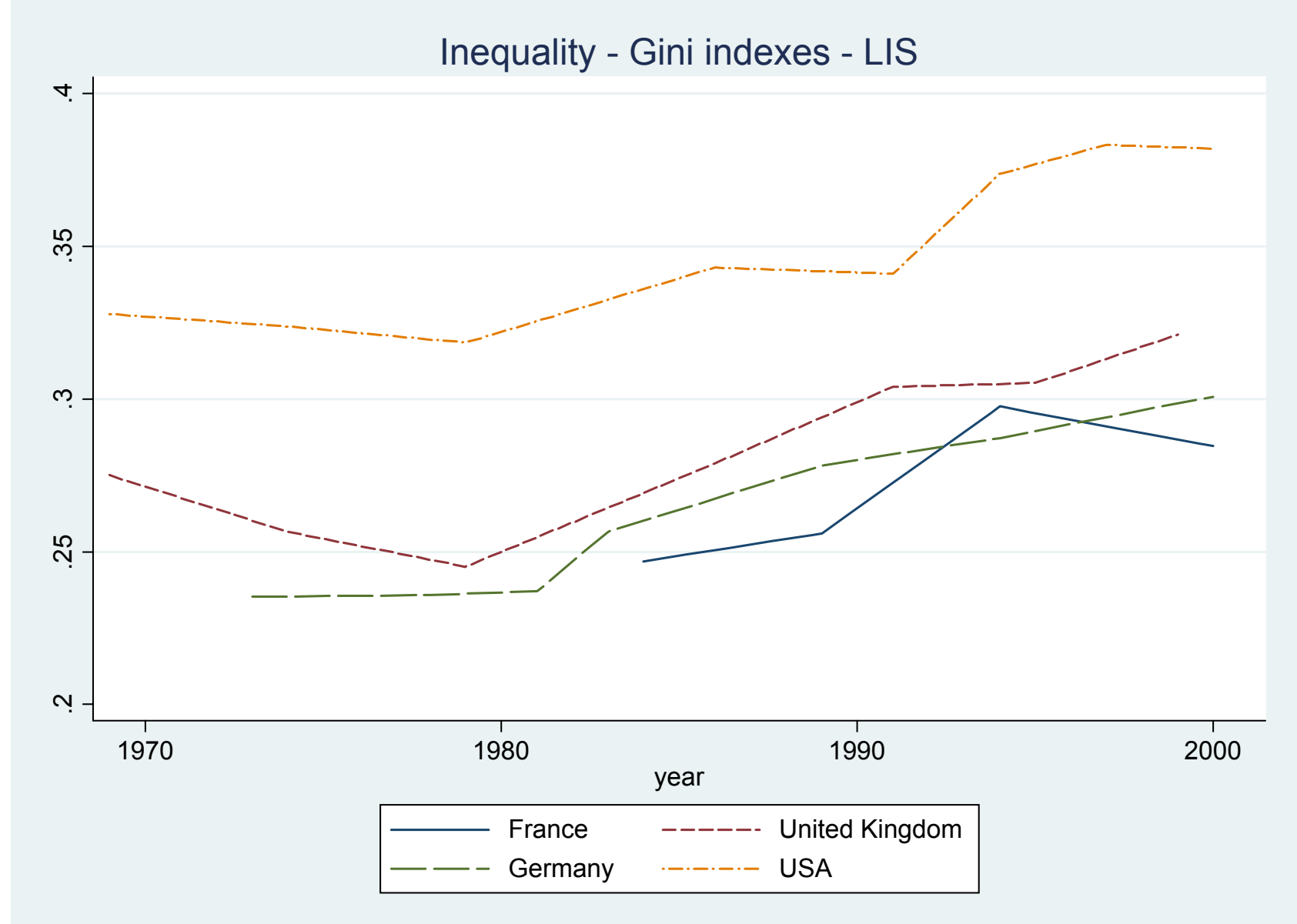


Figure 2 - Wage inequality: p90p10

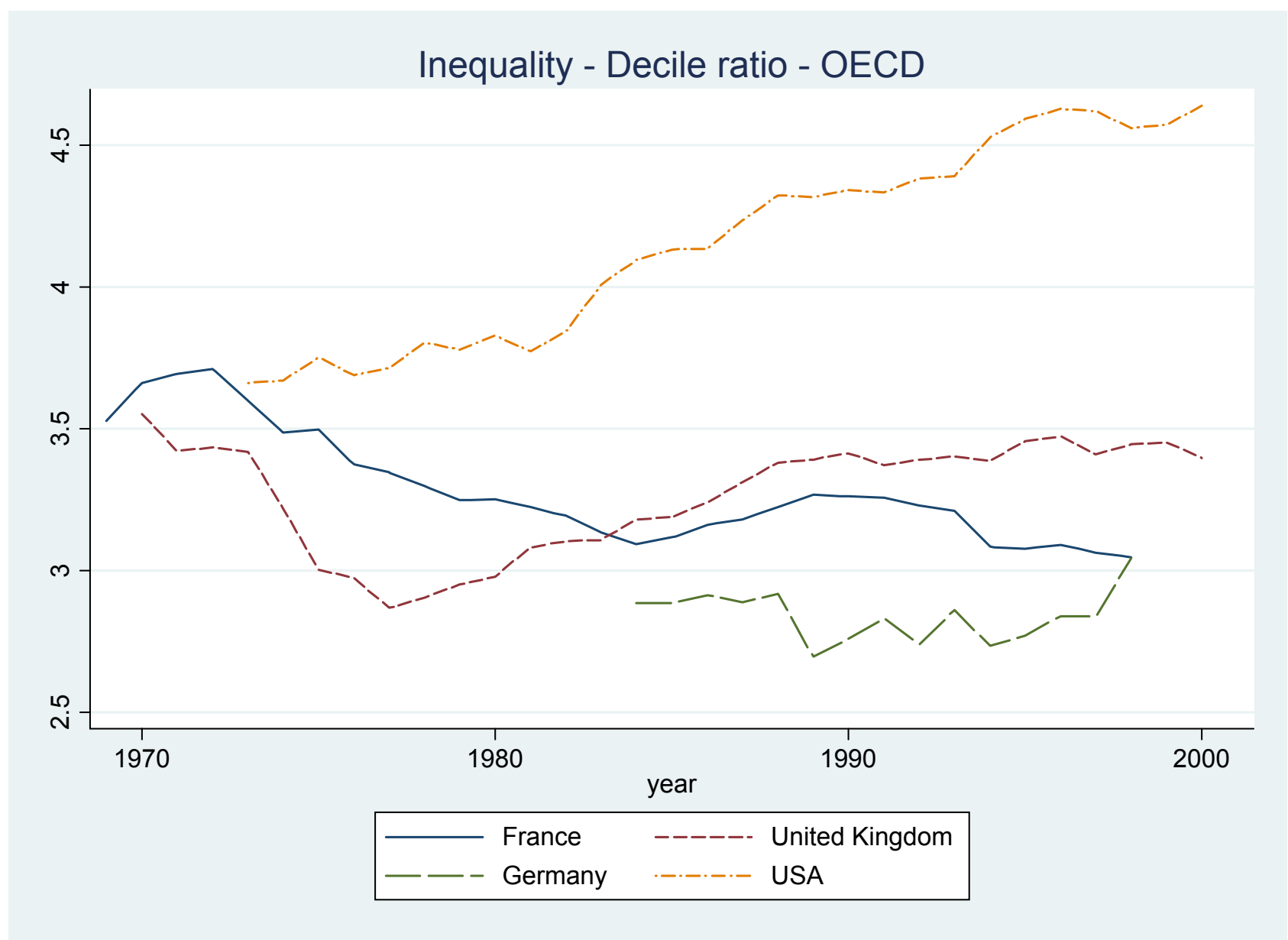


Figure 3 - The labour share

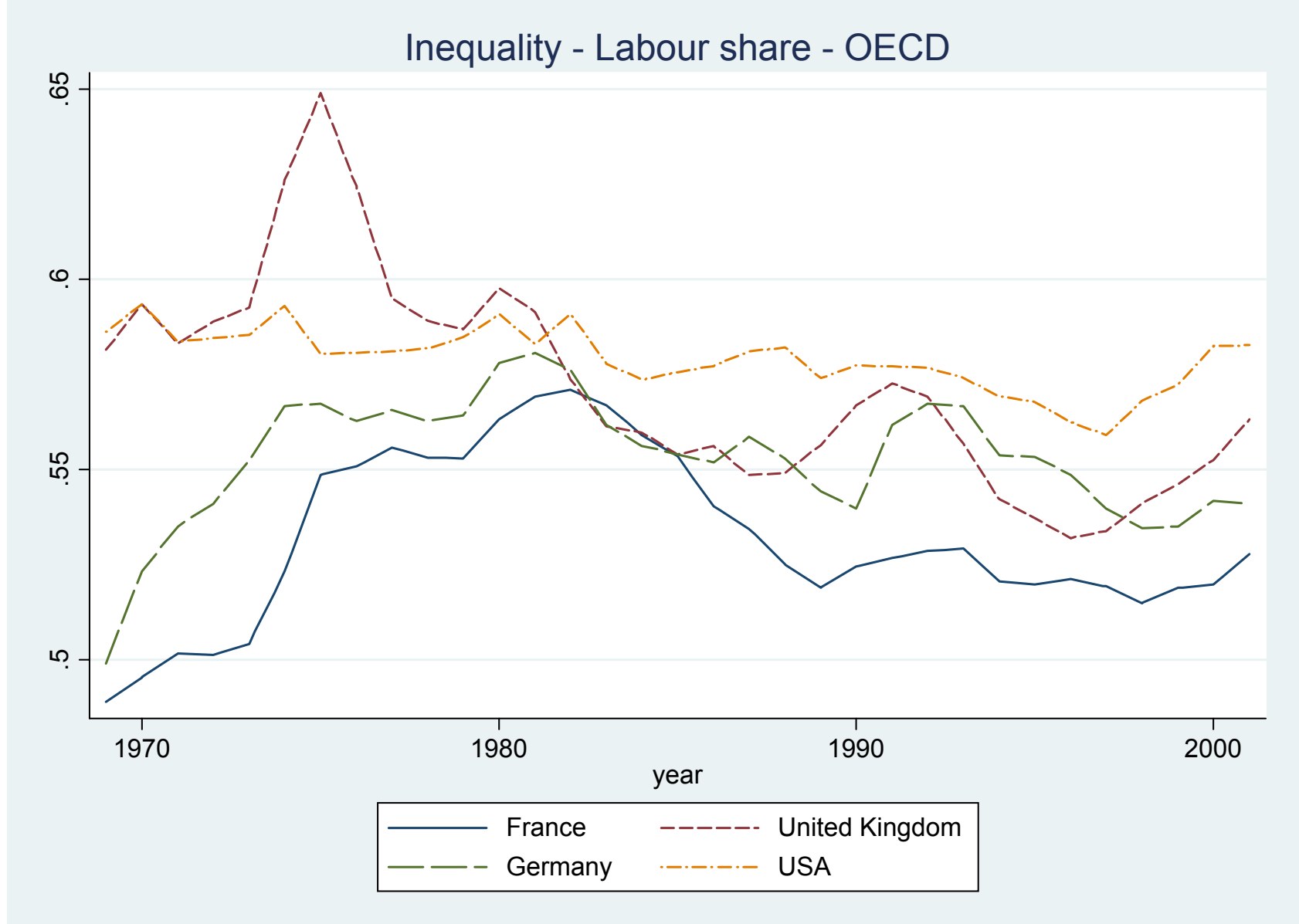


Figure 4 - Gini indices: LIS data

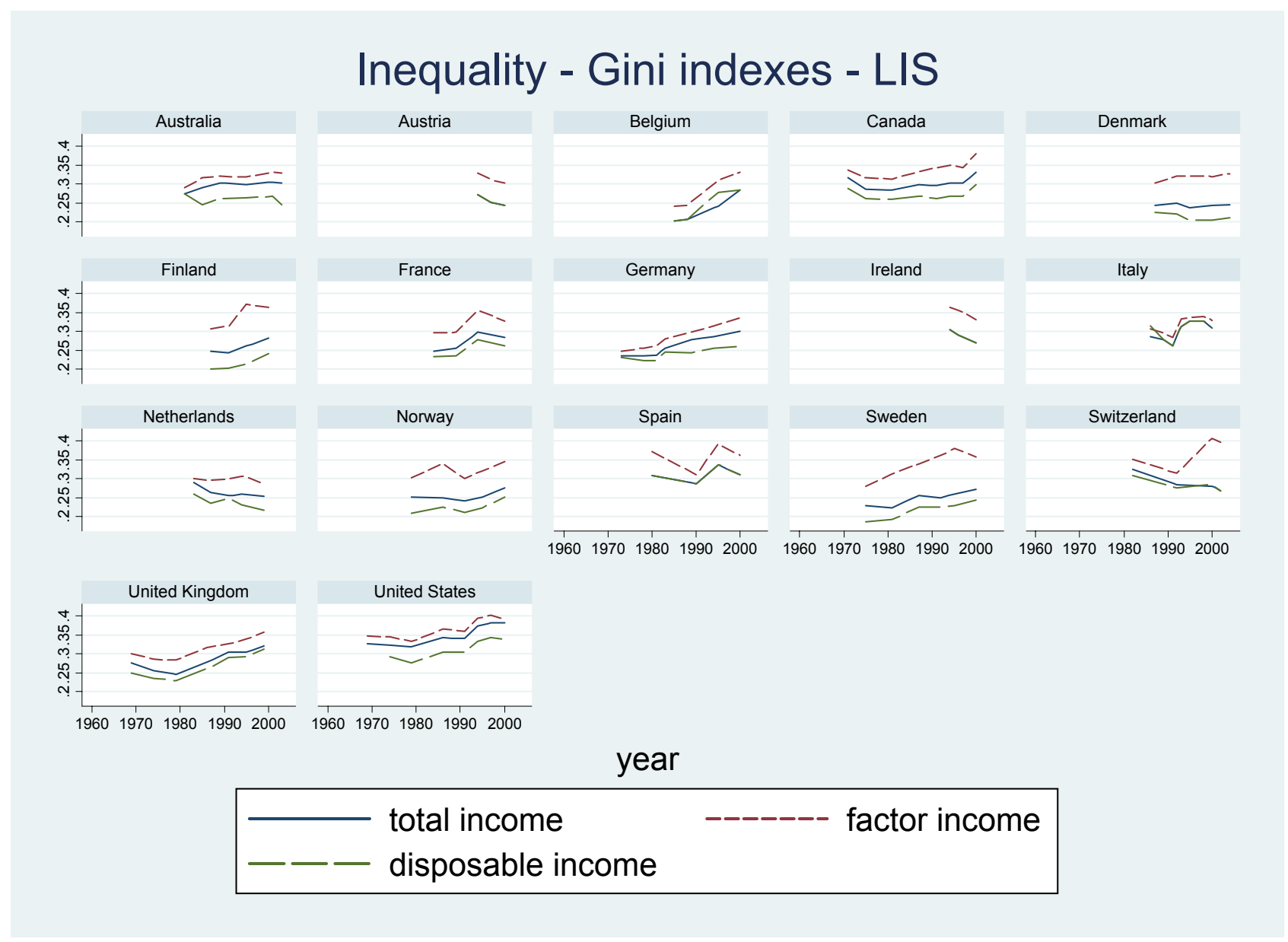


Figure 5 - Wage inequality: Wage decile ratios, LIS data

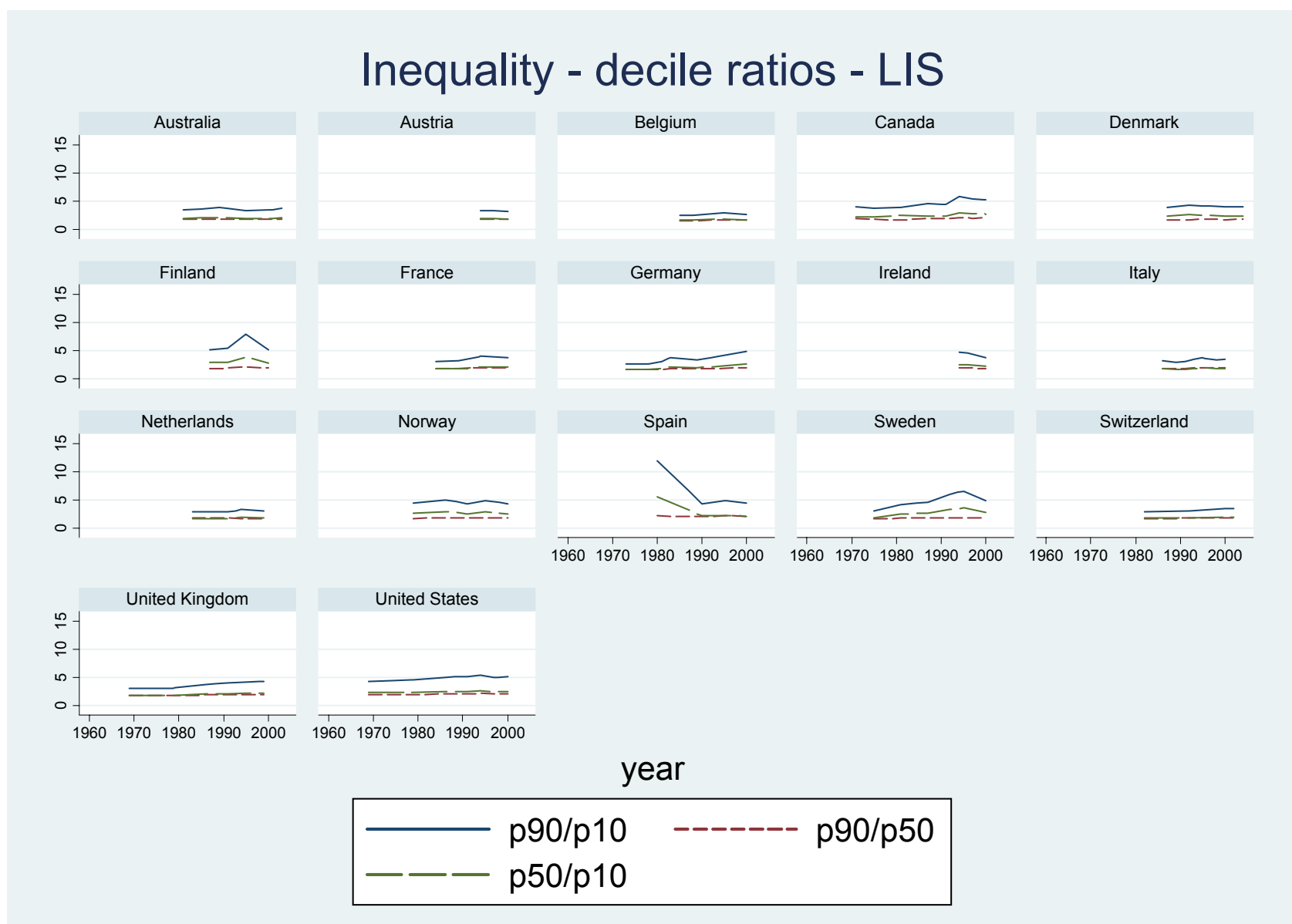


Figure 6 - Wage shares: aggregate and LIS data

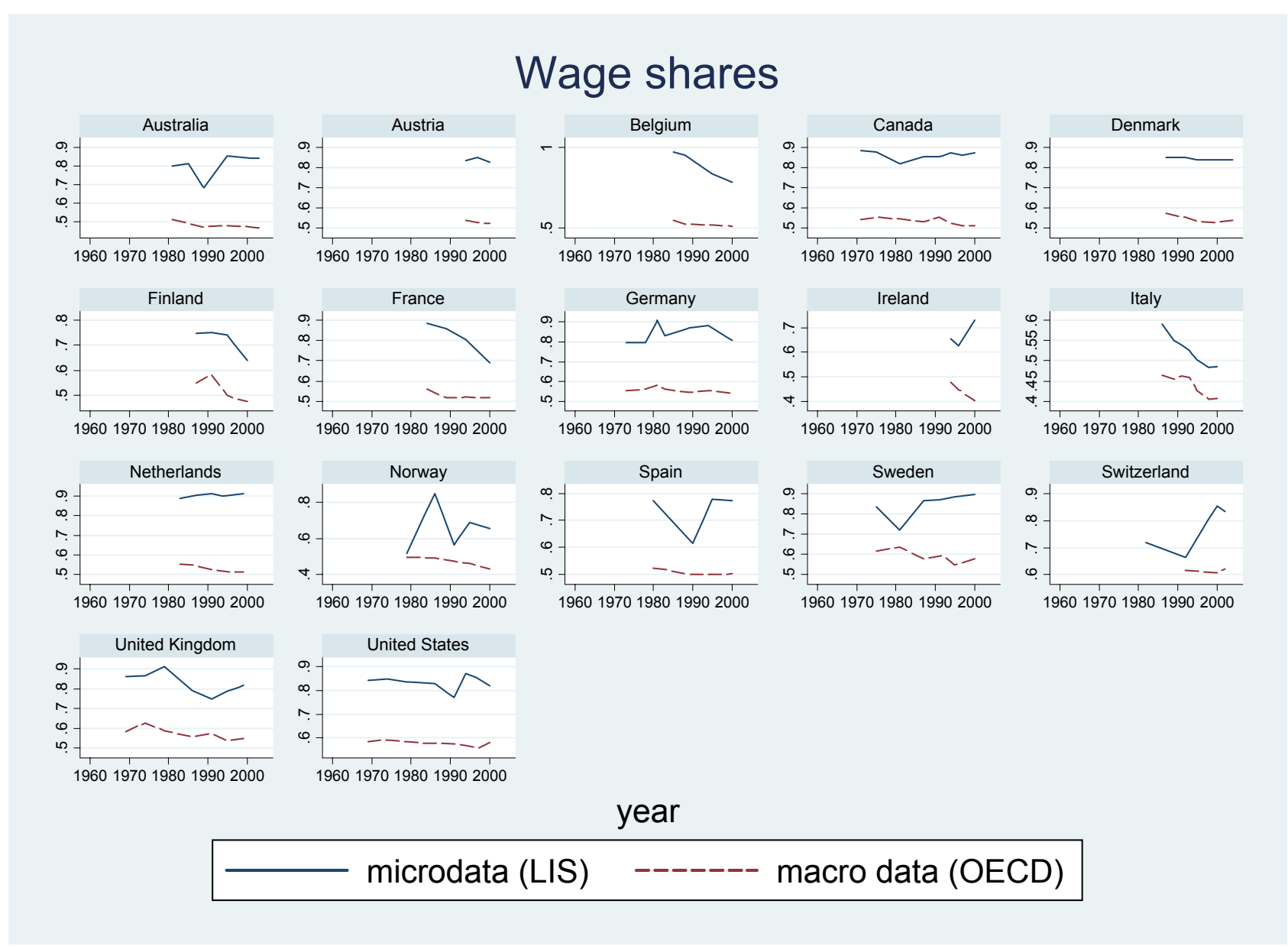


Figure 7

Counterfactuals with US institutions

Union density and unemployment benefit
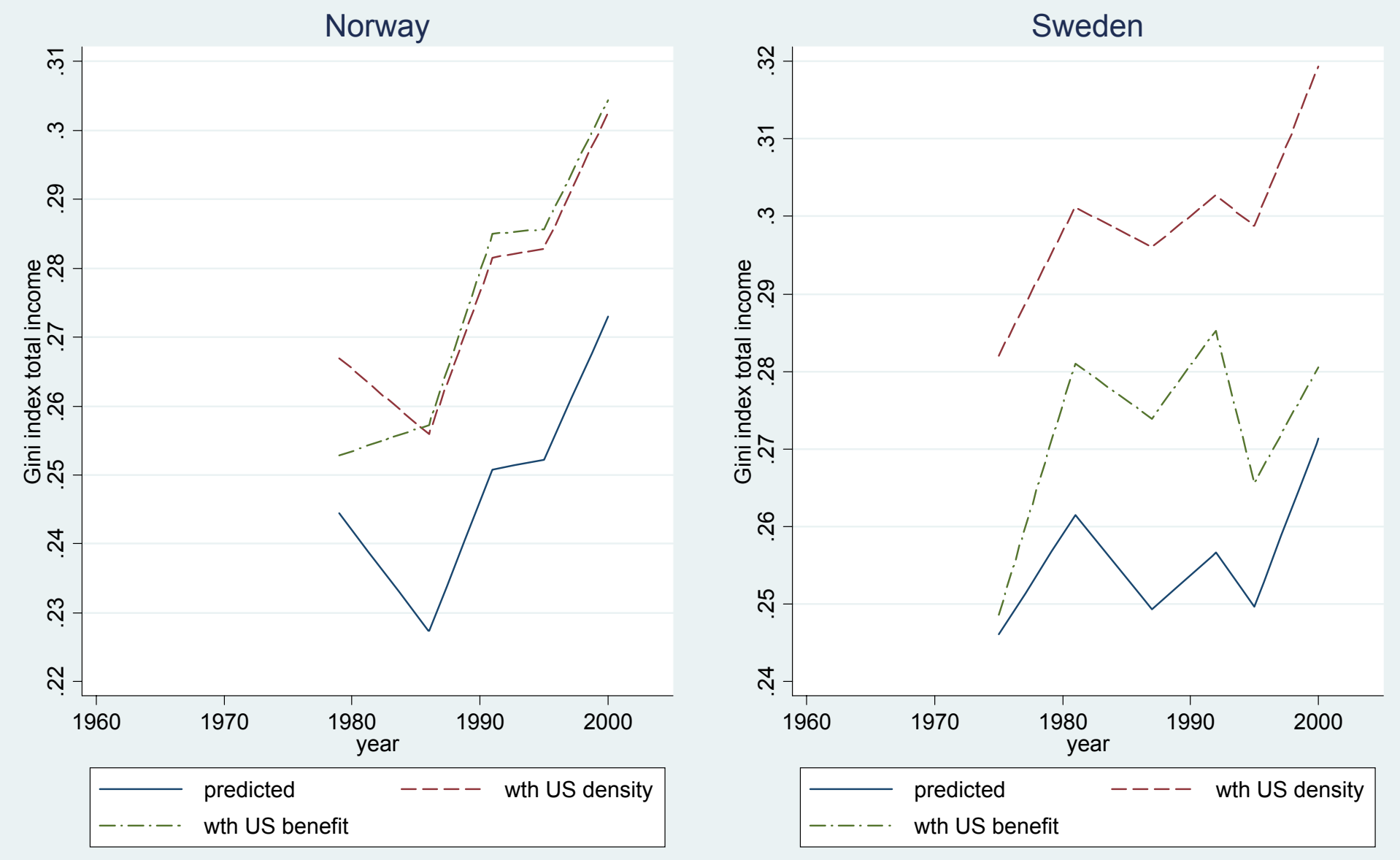


\section{Counterfactuals with UK institutions}

\section{Union density and unemployment benefit}
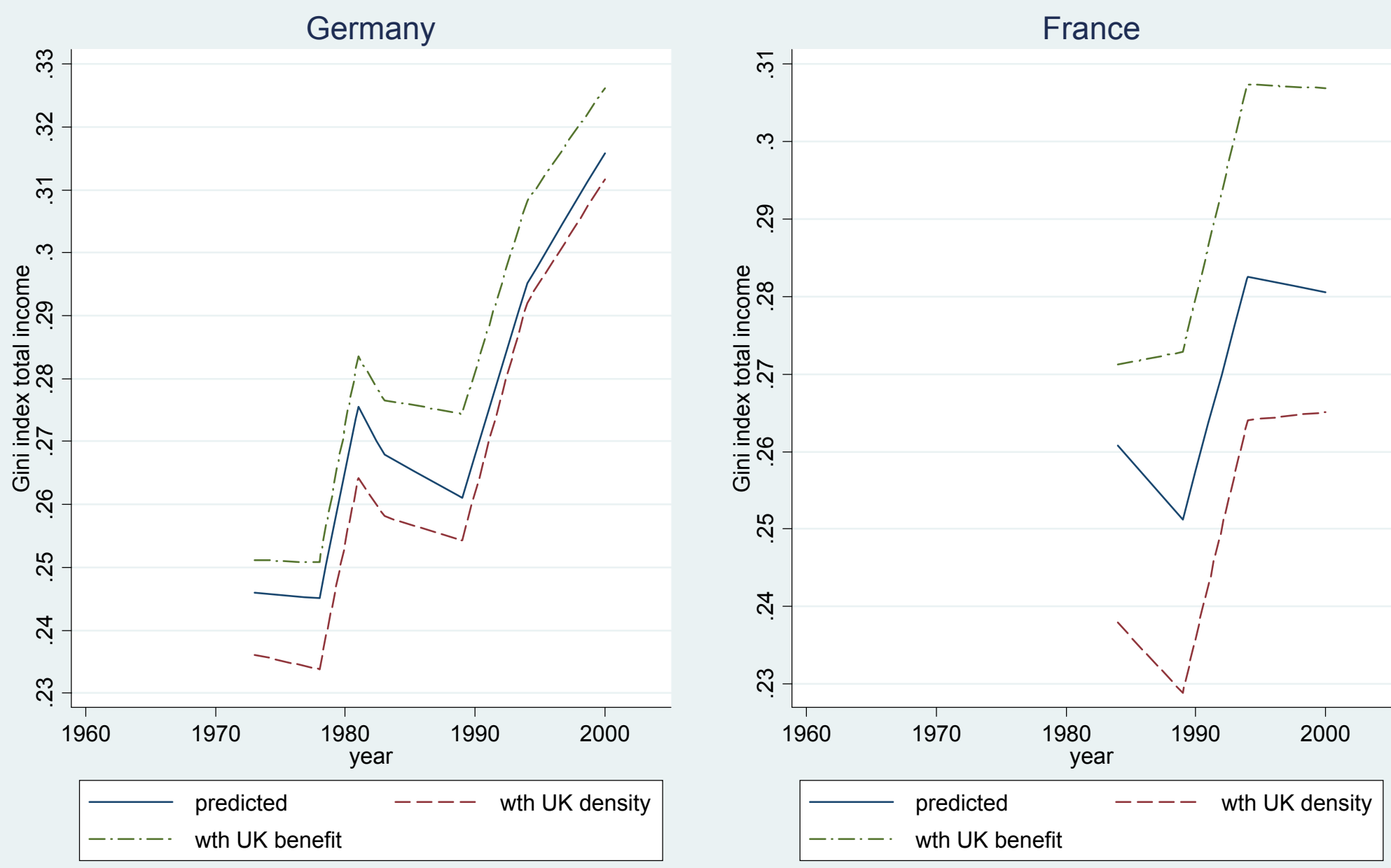
Figure 9

\section{Country position in institutional factors}

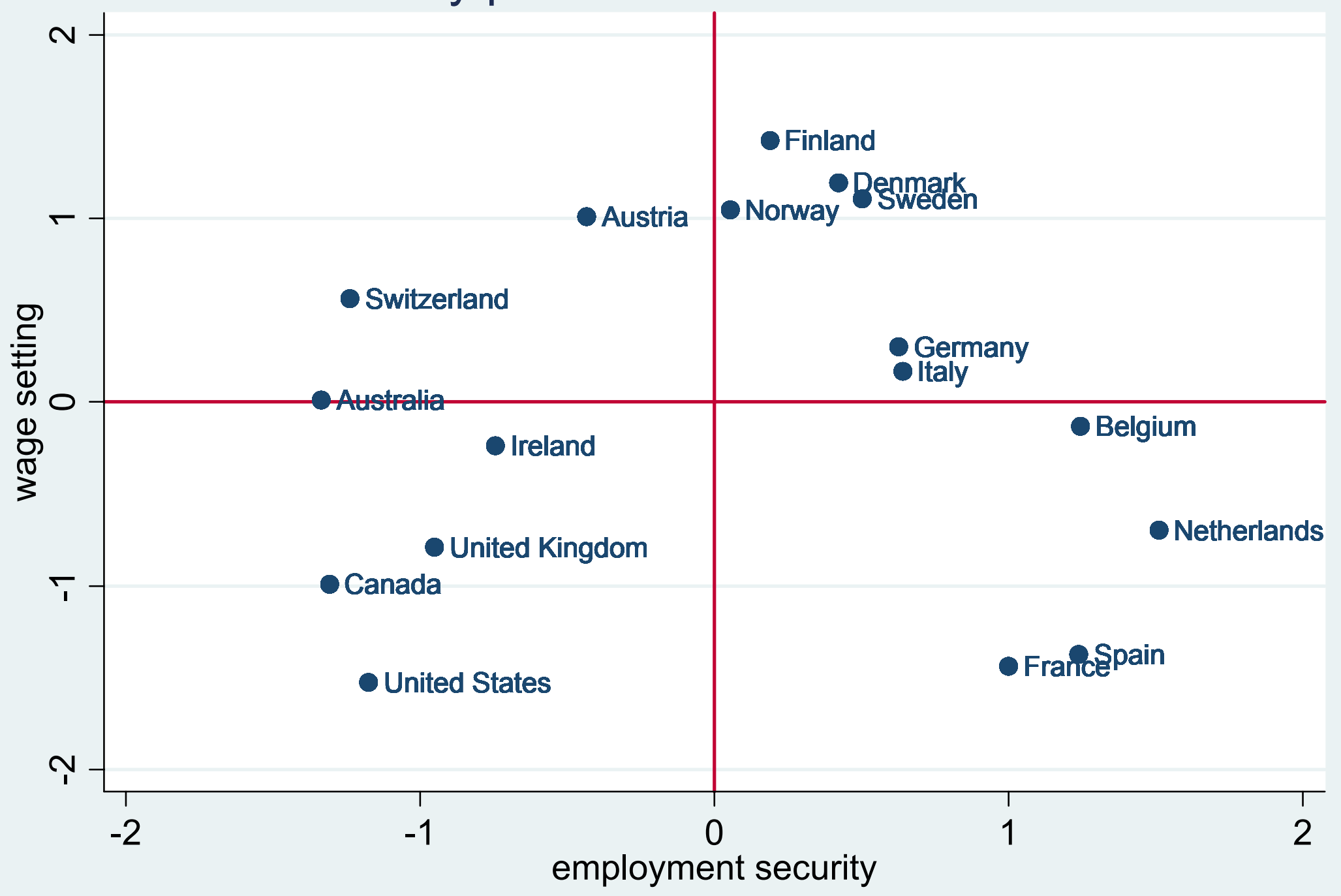


Figure 10

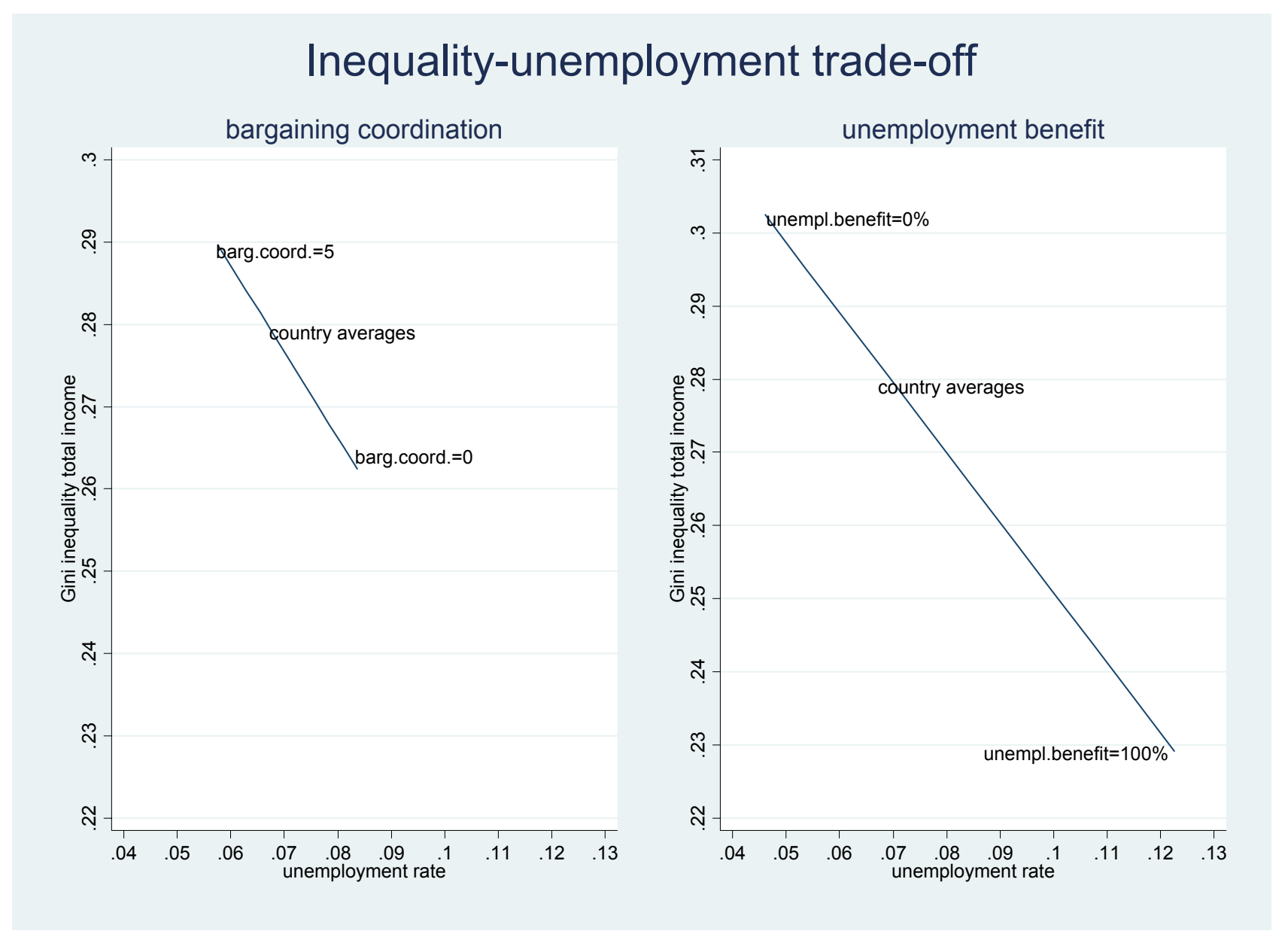




\section{Moving to an European labour standard}

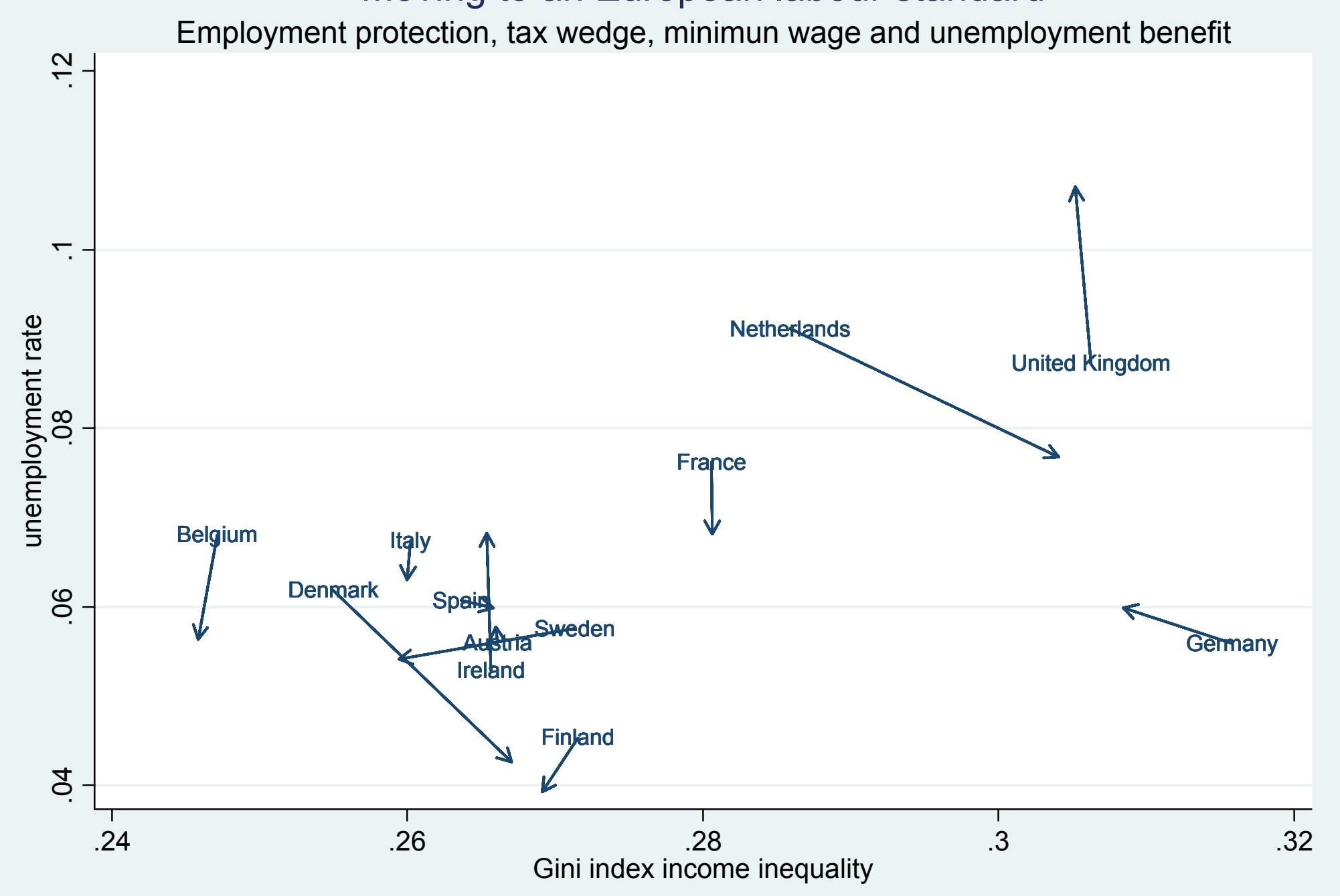




\section{Appendix II: Additional tables}

\begin{tabular}{|c|c|c|c|c|c|c|c|c|}
\hline country & obs & $\begin{array}{c}\text { Gini } \\
\text { index on } \\
\text { total } \\
\text { incomes }\end{array}$ & $\begin{array}{l}\text { Gini } \\
\text { index on } \\
\text { factor } \\
\text { incomes }\end{array}$ & $\begin{array}{l}\text { Gini index } \\
\text { on } \\
\text { disposable } \\
\text { income }\end{array}$ & $\begin{array}{c}\text { decile } \\
\text { ratio } \\
\text { (p90/p50) }\end{array}$ & $\begin{array}{c}\text { decile } \\
\text { ratio } \\
\text { (p50/p10) }\end{array}$ & $\begin{array}{l}\text { wage } \\
\text { share } \\
\text { on } \\
\text { factor } \\
\text { incomes }\end{array}$ & $\begin{array}{l}\text { unemplo- } \\
\text { yment } \\
\text { rate }\end{array}$ \\
\hline \multirow[t]{2}{*}{ Australia } & \multirow[t]{2}{*}{6} & 0.30 & 0.32 & 0.26 & 1.79 & 1.99 & 0.81 & 0.03 \\
\hline & & 0.01 & 0.01 & 0.01 & 0.03 & 0.07 & 0.06 & 0.02 \\
\hline \multirow[t]{2}{*}{ Austria } & \multirow[t]{2}{*}{3} & 0.26 & 0.31 & 0.26 & 1.77 & 1.83 & 0.84 & 0.04 \\
\hline & & 0.01 & 0.01 & 0.01 & 0.02 & 0.07 & 0.01 & 0.00 \\
\hline \multirow[t]{2}{*}{ Belgium } & \multirow[t]{2}{*}{4} & 0.23 & 0.28 & 0.24 & 1.56 & 1.66 & 0.88 & 0.05 \\
\hline & & 0.04 & 0.05 & 0.04 & 0.06 & 0.06 & 0.09 & 0.02 \\
\hline \multirow[t]{2}{*}{ Canada } & \multirow[t]{2}{*}{8} & 0.30 & 0.34 & 0.27 & 1.86 & 2.47 & 0.86 & 0.09 \\
\hline & & 0.02 & 0.02 & 0.01 & 0.15 & 0.28 & 0.02 & 0.03 \\
\hline \multirow[t]{2}{*}{ Czech Republic * } & \multirow[t]{2}{*}{2} & 0.24 & 0.28 & 0.22 & 1.70 & 1.82 & 0.88 & 0.01 \\
\hline & & 0.04 & 0.03 & 0.03 & 0.09 & 0.13 & 0.01 & 0.00 \\
\hline \multirow[t]{2}{*}{ Denmark } & \multirow[t]{2}{*}{5} & 0.24 & 0.32 & 0.21 & 1.68 & 2.41 & 0.84 & 0.09 \\
\hline & & 0.00 & 0.01 & 0.01 & 0.04 & 0.08 & 0.01 & 0.02 \\
\hline \multirow[t]{2}{*}{ Finland } & \multirow[t]{2}{*}{4} & 0.26 & 0.34 & 0.21 & 1.87 & 3.10 & 0.72 & 0.09 \\
\hline & & 0.02 & 0.03 & 0.02 & 0.13 & 0.48 & 0.05 & 0.01 \\
\hline \multirow[t]{2}{*}{ France } & \multirow[t]{2}{*}{4} & 0.27 & 0.32 & 0.25 & 1.81 & 1.90 & 0.81 & 0.05 \\
\hline & & 0.02 & 0.03 & 0.02 & 0.09 & 0.16 & 0.09 & 0.02 \\
\hline \multirow[t]{2}{*}{ Germany } & \multirow[t]{2}{*}{7} & 0.26 & 0.28 & 0.24 & 1.74 & 1.97 & 0.84 & 0.10 \\
\hline & & 0.03 & 0.03 & 0.02 & 0.09 & 0.35 & 0.05 & 0.07 \\
\hline \multirow[t]{2}{*}{ Greece ** } & \multirow[t]{2}{*}{2} & 0.32 & 0.35 & 0.32 & 2.09 & 2.14 & 0.59 & 0.05 \\
\hline & & 0.02 & 0.02 & 0.02 & 1.08 & 1.12 & 0.02 & 0.01 \\
\hline \multirow[t]{2}{*}{ Hungary * } & \multirow[t]{2}{*}{3} & 0.29 & 0.37 & 0.29 & 2.02 & 2.00 & 0.94 & 0.06 \\
\hline & & 0.02 & 0.02 & 0.02 & 0.15 & 0.15 & 0.01 & 0.02 \\
\hline Ireland & 3 & 0.29 & 0.35 & 0.29 & 1.83 & 2.36 & 0.67 & 0.05 \\
\hline & & 0.02 & 0.02 & 0.02 & 0.11 & 0.15 & 0.05 & 0.01 \\
\hline Italy & 7 & 0.30 & 0.32 & 0.30 & 1.84 & 1.75 & 0.53 & 0.01 \\
\hline & & 0.03 & 0.02 & 0.03 & 0.06 & 0.09 & 0.04 & 0.01 \\
\hline Netherlands & 5 & 0.26 & 0.30 & 0.24 & 1.72 & 1.72 & 0.90 & 0.07 \\
\hline & & 0.01 & 0.01 & 0.02 & 0.06 & 0.13 & 0.01 & 0.07 \\
\hline Norway & 5 & 0.25 & 0.32 & 0.22 & 1.71 & 2.67 & 0.65 & 0.07 \\
\hline & & 0.01 & 0.02 & 0.02 & 0.02 & 0.18 & 0.13 & 0.03 \\
\hline Poland * & 4 & 0.27 & 0.31 & 0.28 & 1.83 & 1.80 & 0.82 & 0.04 \\
\hline & & 0.03 & 0.05 & 0.03 & 0.14 & 0.12 & 0.08 & 0.02 \\
\hline Spain & 4 & 0.31 & 0.36 & 0.31 & 2.10 & 2.99 & 0.73 & 0.06 \\
\hline & & 0.02 & 0.03 & 0.02 & 0.07 & 1.71 & 0.08 & 0.02 \\
\hline Sweden & 6 & 0.25 & 0.34 & 0.22 & 1.76 & 2.75 & 0.85 & 0.09 \\
\hline & & 0.02 & 0.04 & 0.02 & 0.07 & 0.62 & 0.06 & 0.02 \\
\hline Switzerland & 4 & 0.29 & 0.37 & 0.28 & 1.74 & 1.84 & 0.77 & 0.03 \\
\hline & & 0.02 & 0.04 & 0.02 & 0.10 & 0.08 & 0.09 & 0.04 \\
\hline United Kingdom & 7 & 0.28 & 0.32 & 0.27 & 1.83 & 1.96 & 0.83 & 0.02 \\
\hline & & 0.03 & 0.03 & 0.03 & 0.09 & 0.22 & 0.06 & 0.01 \\
\hline United States & 8 & 0.35 & 0.37 & 0.31 & 2.01 & 2.41 & 0.83 & 0.05 \\
\hline & & 0.03 & 0.03 & 0.03 & 0.10 & 0.09 & 0.03 & 0.02 \\
\hline Total & 101 & 0.28 & 0.33 & 0.26 & 1.82 & 2.19 & 0.79 & 0.06 \\
\hline & & 0.04 & 0.04 & 0.04 & 0.18 & 0.56 & 0.12 & 0.04 \\
\hline
\end{tabular}


Table A.2 - Descriptive statistics - labour market institutions

first value: mean - second value: standard deviation - third value: observations available

\begin{tabular}{|c|c|c|c|c|c|c|}
\hline country & $\begin{array}{l}\text { union } \\
\text { density }\end{array}$ & $\begin{array}{c}\text { unem.ben. } \\
\text { repl.rate }\end{array}$ & $\begin{array}{l}\text { rmin.wage/ } \\
\text { med.wage }\end{array}$ & $\begin{array}{c}\text { coordin. } \\
\text { wage barg. }\end{array}$ & $\begin{array}{c}\text { empl.protec. } \\
\text { legislat. }\end{array}$ & $\begin{array}{l}\text { tax wedge } \\
\text { couple }\end{array}$ \\
\hline \multirow[t]{3}{*}{ Australia } & 41.56 & 0.22 & 59.33 & 3.33 & 0.96 & 0.13 \\
\hline & 8.98 & 0.04 & 5.03 & 1.06 & 0.12 & 0.03 \\
\hline & 45 & 44 & 28 & 32 & 45 & 45 \\
\hline \multirow[t]{3}{*}{ Austria } & 51.19 & 0.26 & 100.00 & 4.39 & 1.74 & 0.24 \\
\hline & 9.42 & 0.06 & 0.00 & 0.45 & 0.50 & 0.04 \\
\hline & 45 & 44 & 45 & 32 & 45 & 45 \\
\hline \multirow[t]{3}{*}{ Belgium } & 49.48 & 0.41 & 53.48 & 4.03 & 2.76 & 0.37 \\
\hline & 6.29 & 0.04 & 3.47 & 0.31 & 0.63 & 0.03 \\
\hline & 45 & 44 & 29 & 32 & 45 & 45 \\
\hline \multirow[t]{3}{*}{ Canada } & 32.24 & 0.17 & 44.06 & 1.31 & 0.80 & 0.16 \\
\hline & 2.95 & 0.03 & 4.39 & 0.74 & 0.00 & 0.05 \\
\hline & 45 & 44 & 39 & 32 & 45 & 45 \\
\hline \multirow[t]{3}{*}{ Czech Republic } & 43.52 & 0.06 & 33.36 & 1 & 1.90 & 0.26 \\
\hline & 18.82 & 0.00 & 9.04 & 0.00 & 0.00 & 0.03 \\
\hline & 15 & 4 & 13 & 12 & 11 & 12 \\
\hline \multirow[t]{3}{*}{ Denmark } & 70.82 & 0.44 & 100.00 & 4 & 2.05 & 0.29 \\
\hline & 8.20 & 0.14 & 0.00 & 0.80 & 0.38 & 0.06 \\
\hline & 45 & 44 & 45 & 32 & 45 & 45 \\
\hline \multirow[t]{3}{*}{ Finland } & 63.38 & 0.25 & 100.00 & 4.84 & 2.25 & 0.33 \\
\hline & 15.06 & 0.13 & 0.00 & 0.37 & 0.11 & 0.06 \\
\hline & 45 & 44 & 45 & 32 & 45 & 45 \\
\hline \multirow[t]{3}{*}{ France } & 15.59 & 0.31 & 55.49 & 2 & 2.32 & 0.35 \\
\hline & 5.09 & 0.06 & 5.91 & 0.00 & 0.82 & 0.04 \\
\hline & 45 & 44 & 43 & 32 & 45 & 45 \\
\hline \multirow[t]{3}{*}{ Germany } & 31.74 & 0.29 & 100.00 & 4 & 2.61 & 0.32 \\
\hline & 3.83 & 0.01 & 0.00 & 0.00 & 0.83 & 0.03 \\
\hline & 45 & 44 & 45 & 32 & 45 & 45 \\
\hline \multirow[t]{3}{*}{ Greece } & 32.16 & 0.09 & 65.04 & . & 3.50 & 0.28 \\
\hline & 5.10 & 0.04 & 13.06 & . & 0.16 & 0.10 \\
\hline & 28 & 44 & 41 & . & 22 & 26 \\
\hline \multirow[t]{3}{*}{ Hungary } & 33.80 & 0.13 & 40.34 & 1 & 1.31 & 0.36 \\
\hline & 15.94 & 0.00 & 4.29 & 0.00 & 0.05 & 0.04 \\
\hline & 9 & 4 & 15 & 12 & 14 & 10 \\
\hline \multirow[t]{3}{*}{ Ireland } & 48.76 & 0.25 & 39.72 & 3.30 & 0.69 & 0.22 \\
\hline & 7.46 & 0.06 & 0.40 & 1.14 & 0.33 & 0.06 \\
\hline & 45 & 44 & 44 & 32 & 45 & 45 \\
\hline \multirow[t]{3}{*}{ Italy } & 38.02 & 0.09 & 100.00 & 2.83 & 3.39 & 0.39 \\
\hline & 7.80 & 0.12 & 0.00 & 0.85 & 0.50 & 0.03 \\
\hline & 45 & 44 & 45 & 32 & 45 & 45 \\
\hline \multirow[t]{3}{*}{ Netherlands } & 31.65 & 0.47 & 57.99 & 3.92 & 2.63 & 0.38 \\
\hline & 6.56 & 0.10 & 5.77 & 0.44 & 0.21 & 0.04 \\
\hline & 45 & 44 & 40 & 32 & 45 & 45 \\
\hline \multirow[t]{3}{*}{ Norway } & 56.66 & 0.24 & 100.00 & 4.34 & 2.86 & 0.26 \\
\hline & 2.16 & 0.16 & 0.00 & 0.37 & 0.12 & 0.03 \\
\hline & 45 & 44 & 45 & 32 & 45 & 40 \\
\hline \multirow[t]{3}{*}{ Poland } & 23.66 & 0.11 & 41.45 & 1 & 1.50 & 0.39 \\
\hline & 10.86 & 0.00 & 4.69 & 0.00 & 0.09 & 0.01 \\
\hline & 11 & 4 & 14 & 12 & 14 & 10 \\
\hline \multirow[t]{3}{*}{ Spain } & 15.29 & 0.26 & 41.11 & 3.70 & 3.74 & 0.29 \\
\hline & 8.79 & 0.10 & 8.55 & 0.71 & 0.42 & 0.05 \\
\hline & 27 & 44 & 38 & 32 & 45 & 41 \\
\hline Sweden & 76.21 & 0.20 & 100.00 & 3.39 & 2.16 & 0.37 \\
\hline & 5.68 & 0.10 & 0.00 & 0.45 & 1.35 & 0.08 \\
\hline & 45 & 44 & 45 & 32 & 45 & 45 \\
\hline Switzerland & 27.49 & 0.16 & 100.00 & 4 & 1.10 & 0.18 \\
\hline & 4.93 & 0.13 & 0.00 & 0.00 & 0.00 & 0.02 \\
\hline & 45 & 44 & 45 & 32 & 45 & 45 \\
\hline
\end{tabular}




\begin{tabular}{l|cccccc}
\hline United Kingdom & 41.06 & 0.22 & 42.94 & 1.78 & 0.53 & 0.23 \\
& 6.73 & 0.04 & 0.30 & 1.21 & 0.14 & 0.04 \\
& 45 & 44 & 44 & 32 & 45 & 45 \\
\hline United States & 20.41 & 0.12 & 42.14 & 1 & 0.20 & 0.22 \\
& 6 & 0.02 & 6.50 & 0.00 & 0.00 & 0.03 \\
& 45 & 44 & 44 & 32 & 45 & 45 \\
\hline Total & 41.81 & 0.25 & 71.94 & 3.16 & 1.95 & 0.28 \\
& 18.60 & 0.14 & 26.89 & 1.36 & 1.13 & 0.09 \\
& 810 & 804 & 792 & 580 & 826 & 814
\end{tabular}


Table A.3 - Determinants of total income inequality - IV regressions - various income definitions - regional controls

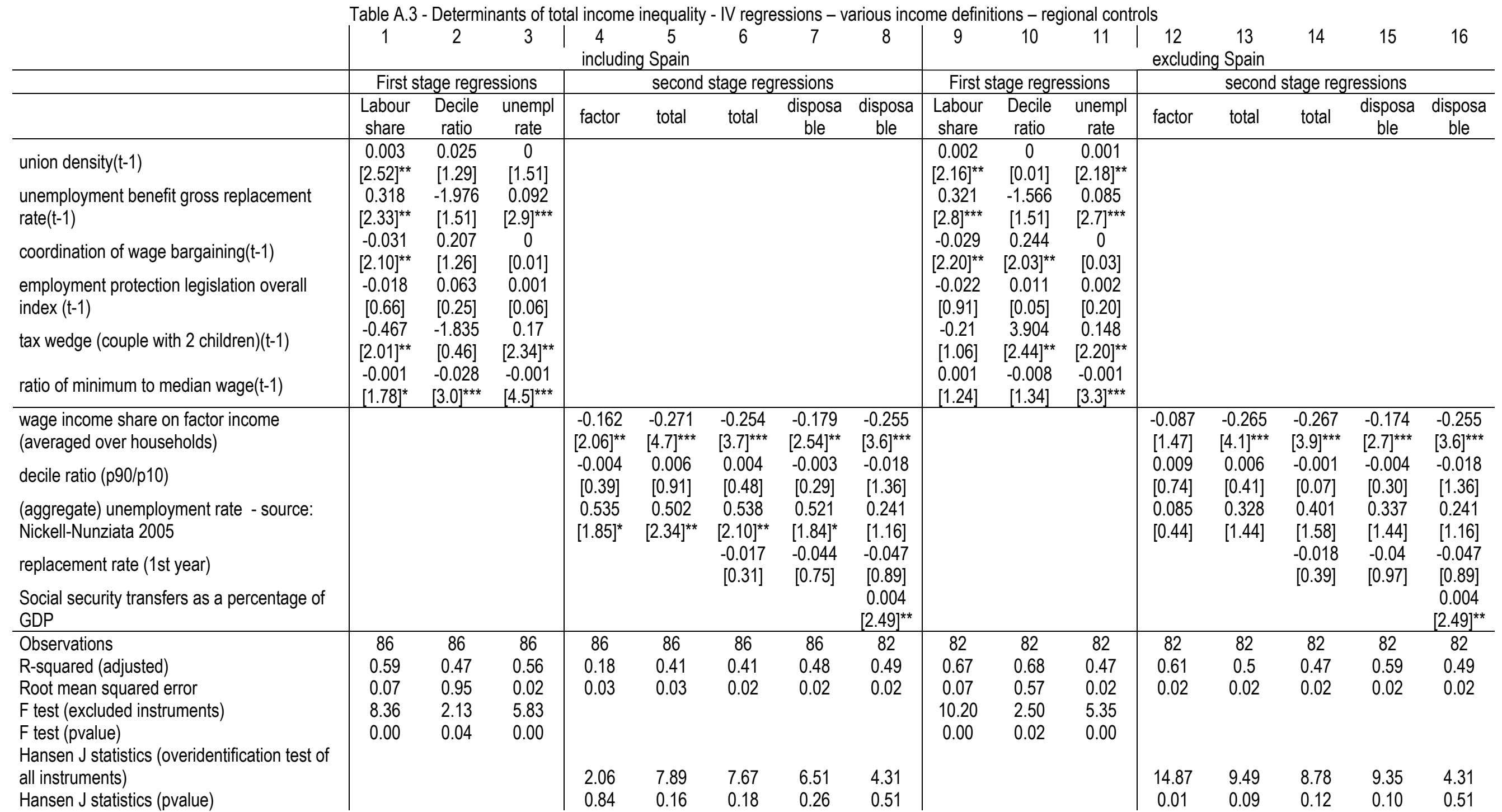

Hansen J statistics (pvalue)

Robust t statistics in brackets * significant at 10\%; ${ }^{* *}$ significant at $5 \%$; ${ }^{* * *}$ significant at $1 \%$ Controls for regions, decade, education, gender, age, investment and trade openness included IV: lagged density benefit, coordination, epl, tax wedge, min.wage. Regional controls include "Anglo-Saxon" (Australia, Ireland, Switzerland, United Kingdom), "Scandinavia" (Denmark, Finland, Norway,

Sweden), "Continental Europe" (Austria, Belgium, France, Germany, Italy, Netherlands, Spain) and "North America" (Canada, United States). Countries (observations) included are: Australia (5),

Austria (3), Belgium (4), Canada (8), Denmark (4), Finland (4), France (4), Germany (7), Ireland (3), Italy (7), Netherlands (5), Norway (5), Spain (4), Sweden (6), Switzerland (4), United Kingdom

(6), United States (7). Spain is excluded in column 8 because lack of information on social transfer 
Table A.4 - Determinants of total income inequality - IV regressions - various income definitions - country fixed effects

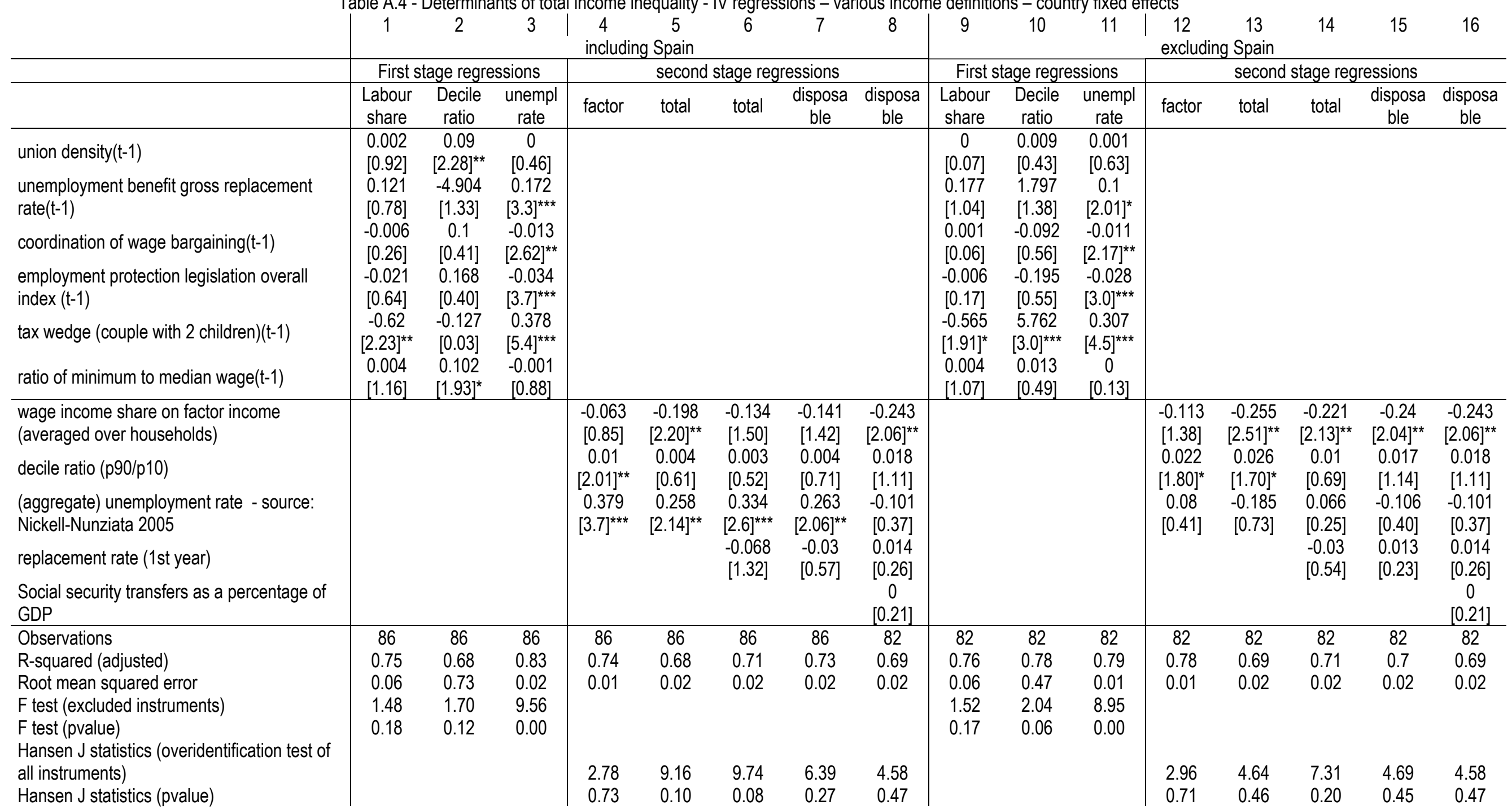

Robust t statistics in brackets * significant at 10\%; ${ }^{* *}$ significant at $5 \%$; ${ }^{* * *}$ significant at $1 \%$ Controls for countries, decade, education, gender, age, investment and trade openness included IV: lagged density benefit, coordination, epl, tax wedge, min.wage. Spain is excluded in column 8 because lack of information on social transfer 
Table A.5 - Determinants of total income inequality - robustness - excluding each country in turn

\begin{tabular}{|c|c|c|c|c|c|c|c|c|c|c|c|c|c|c|c|c|c|c|}
\hline EXCLUDED: & $\begin{array}{c}1 \\
\text { none }\end{array}$ & $\begin{array}{c}2 \\
\text { Australia }\end{array}$ & $\begin{array}{c}3 \\
\text { Austria }\end{array}$ & $\begin{array}{c}4 \\
\text { Belgium }\end{array}$ & $\begin{array}{c}5 \\
\text { Canada }\end{array}$ & $\begin{array}{c}6 \\
\text { Denmark }\end{array}$ & $\begin{array}{c}7 \\
\text { Finland }\end{array}$ & $\begin{array}{c}8 \\
\text { France }\end{array}$ & $\begin{array}{c}9 \\
\text { Germany }\end{array}$ & $\begin{array}{c}10 \\
\text { Ireland }\end{array}$ & $\begin{array}{c}11 \\
\text { Italy }\end{array}$ & $\begin{array}{c}12 \\
\text { Netherland }\end{array}$ & $\begin{array}{c}13 \\
\text { Norway }\end{array}$ & $\begin{array}{c}14 \\
\text { Spain }\end{array}$ & $\begin{array}{c}15 \\
\text { Sweden }\end{array}$ & $\begin{array}{c}16 \\
\text { Switzerland }\end{array}$ & $\begin{array}{l}17 \\
\text { UK }\end{array}$ & $\begin{array}{c}18 \\
\text { USA }\end{array}$ \\
\hline wage income share on & -0.271 & -0.281 & -0.329 & -0.251 & -0.174 & -0.274 & -0.277 & -0.289 & -0.266 & -0.276 & -0.243 & -0.262 & -0.242 & -0.265 & -0.184 & -0.238 & -0.221 & -0.183 \\
\hline over households) & {$[4.77]^{\star * *}$} & {$[4.87]^{\star * *}$} & {$[3.54]^{* * *}$} & {$[4.48]^{\star * *}$} & {$[4.95]^{\star * *}$} & {$[4.70]^{\star * *}$} & {$[4.92]^{* * *}$} & {$[4.25]^{\star * *}$} & {$[5.04]^{* * *}$} & {$[4.49]^{* * *}$} & {$[4.08]^{* * *}$} & {$[5.00]^{* * *}$} & {$[6.10]^{\star * *}$} & {$[4.09]^{* * *}$} & {$[5.37]^{\star * *}$} & {$[4.65]^{* * *}$} & {$[4.83]^{* * *}$} & {$[4.84]^{\star * *}$} \\
\hline & 0.006 & 0.006 & 0.003 & 0.003 & 0.006 & 0.01 & 0.009 & 0.003 & 0.007 & 0.005 & 0.013 & 0.009 & 0.01 & 0.006 & 0.014 & 0.01 & 0.007 & 0.003 \\
\hline decile ratıo (p9o/ & {$[0.91]$} & {$[1.01]$} & {$[0.38]$} & {$[0.40]$} & [1.64] & {$[1.56]$} & {$[1.84]^{*}$} & {$[0.44]$} & [1.15] & {$[0.73]$} & {$[2.53]^{\star \star}$} & [1.32] & {$[2.47]^{* \star}$} & {$[0.41]$} & {$[2.38]^{\star *}$} & {$[1.75]^{*}$} & [1.35] & {$[0.77]$} \\
\hline (aggregate) unemployment & 0.502 & 0.507 & 0.805 & 0.53 & 0.282 & 0.41 & 0.415 & 0.567 & 0.47 & 0.549 & 0.353 & 0.41 & 0.314 & 0.328 & 0.162 & 0.576 & 0.438 & 0.316 \\
\hline Nunziata 2005 & {$[2.34]^{* *}$} & {$[2.32]^{* *}$} & {$[2.09]^{* *}$} & {$[2.74]^{\star \star *}$} & {$[2.34]^{* *}$} & {$[2.13]^{* *}$} & {$[2.08]^{* *}$} & {$[2.29]^{* *}$} & {$[2.41]^{* *}$} & {$[2.38]^{* *}$} & {$[1.95]^{*}$} & {$[2.04]^{* *}$} & {$[2.01]^{* *}$} & [1.44] & [1.18] & {$[2.78]^{\star * *}$} & {$[2.26]^{* *}$} & {$[2.46]^{* *}$} \\
\hline R-squared (adjusted) & 41 & .38 & 0.17 & 0.36 & 0.72 & 0.44 & 0.5 & 0.32 & 0.44 & 0.37 & 0.48 & 0.46 & 0.55 & 0.5 & 0.6 & 0.44 & 0.51 & 0.55 \\
\hline $\begin{array}{l}\text { Root men squared error } \\
\text { Hansen J statistics }\end{array}$ & 0.03 & 0.03 & 0.03 & 0.03 & 0.02 & 0.02 & 0.02 & 0.03 & 0.02 & 0.03 & 0.02 & 0.02 & 0.02 & 0.02 & 0.02 & 0.02 & 0.02 & 0.02 \\
\hline & 7.89 & & 6.74 & 6.76 & & & $10 . \angle 0$ & 7.09 & & & & & & & & 7.13 & 15.52 & 7.01 \\
\hline Hansen J statistics pvalue & 0.16 & 0.23 & 0.24 & 0.24 & 0.09 & 0.11 & 0.07 & 0.21 & 0.17 & 0.27 & 0.05 & 0.1 & 0.02 & 0.09 & 0.01 & 0.21 & 0.01 & 0.22 \\
\hline
\end{tabular}

Robust z statistics in brackets - * significant at 10\%; ${ }^{* *}$ significant at $5 \%$; ${ }^{* * *}$ significant at $1 \%$

Controls for regions, decades, education, gender, age, investment and trade openness.

Included IV: lagged density benefit, coordination, epl, tax wedge, min.wage. 
Table A.6 - Reduced form - various income definition - comparison between fixed and random effect

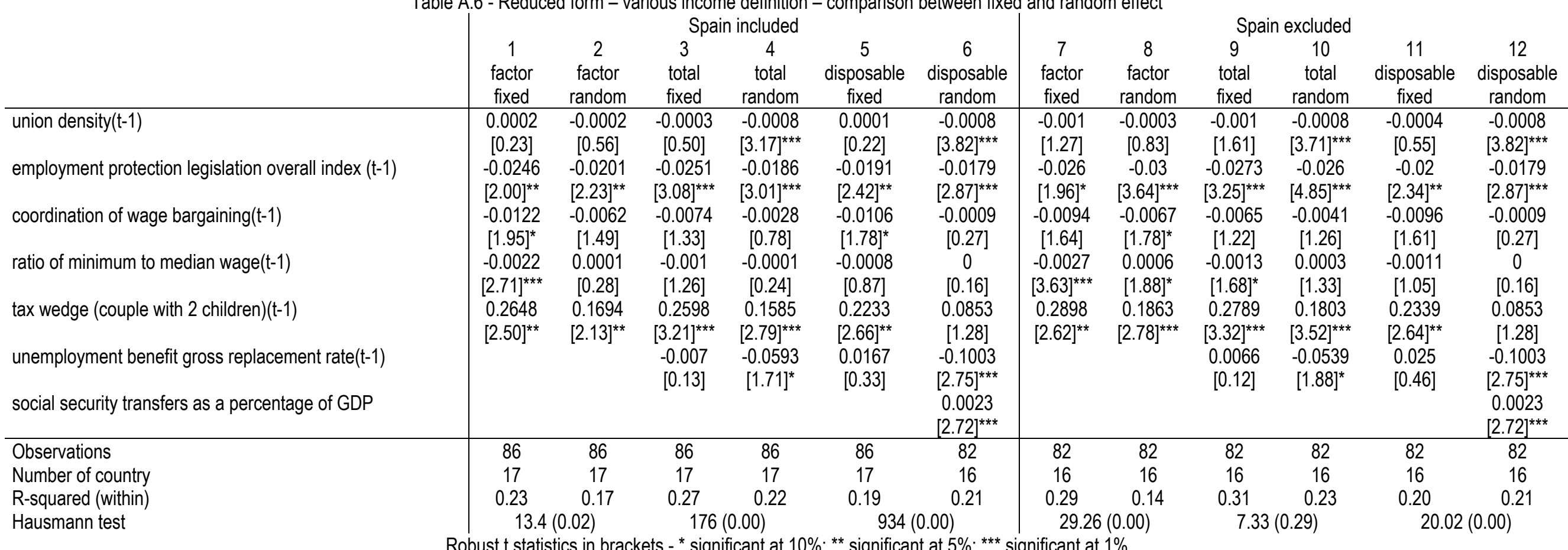

Additional controls and variables interactions are suppressed, because otherwise the small sample would prevent the Hausman test to converge 
Figure A.1 - Actual and predicted values of Gini

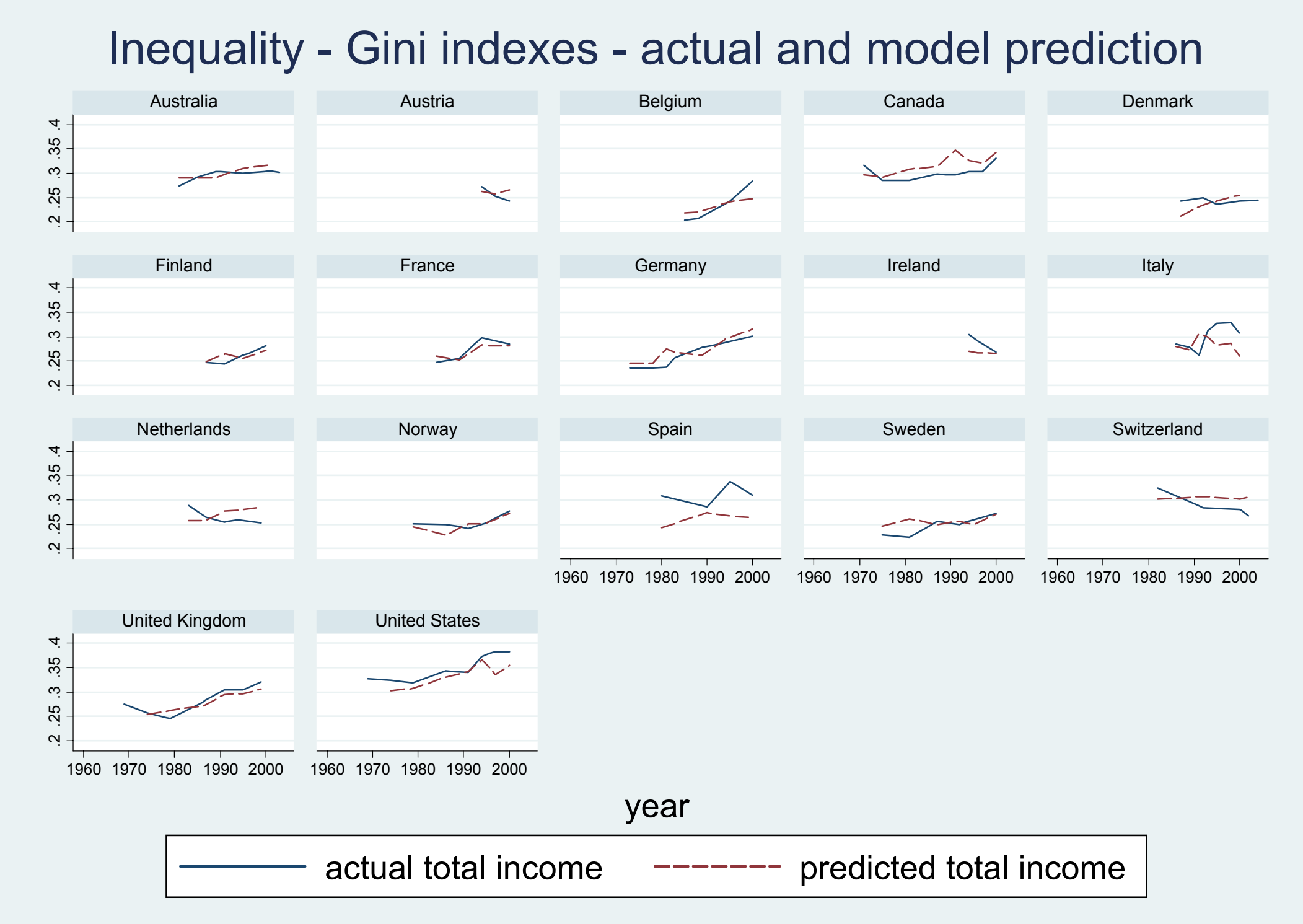


Figure A.2 - Actual and predicted values of the wage share

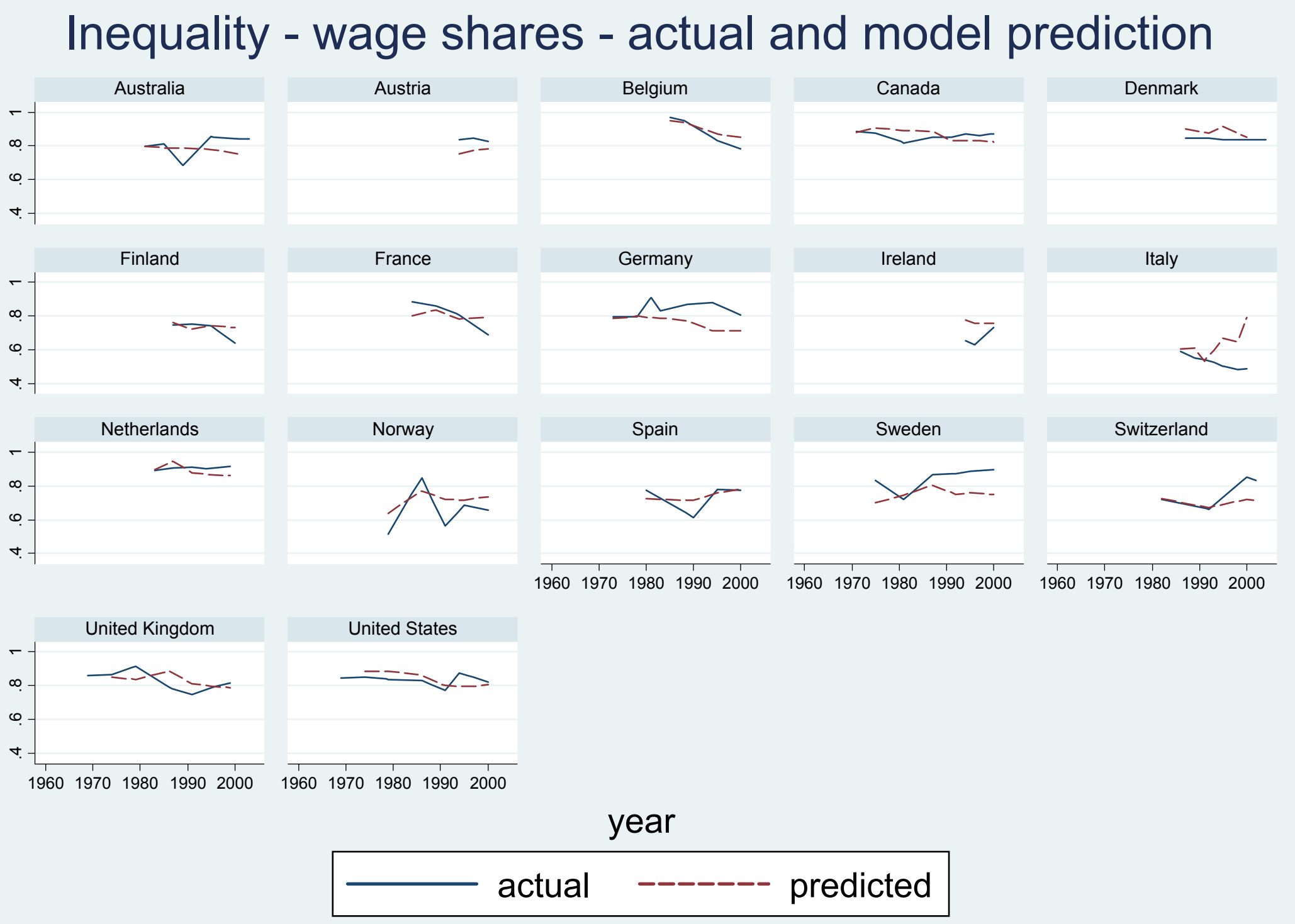




\section{Inequality - decile ratio p90/p10 - actual and model prediction}
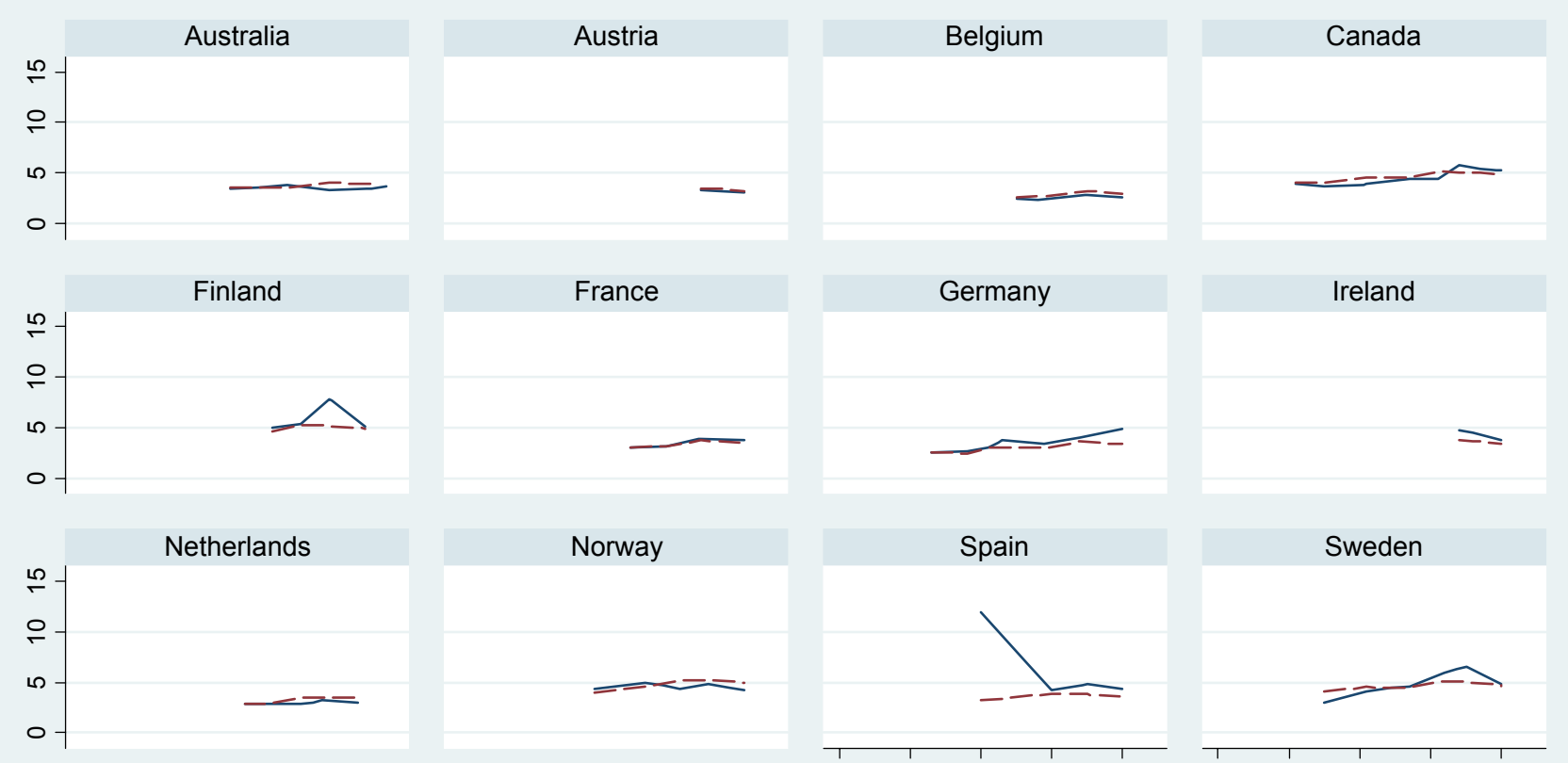

France

Germany

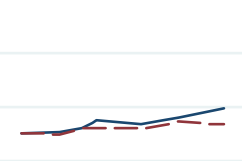

Norway
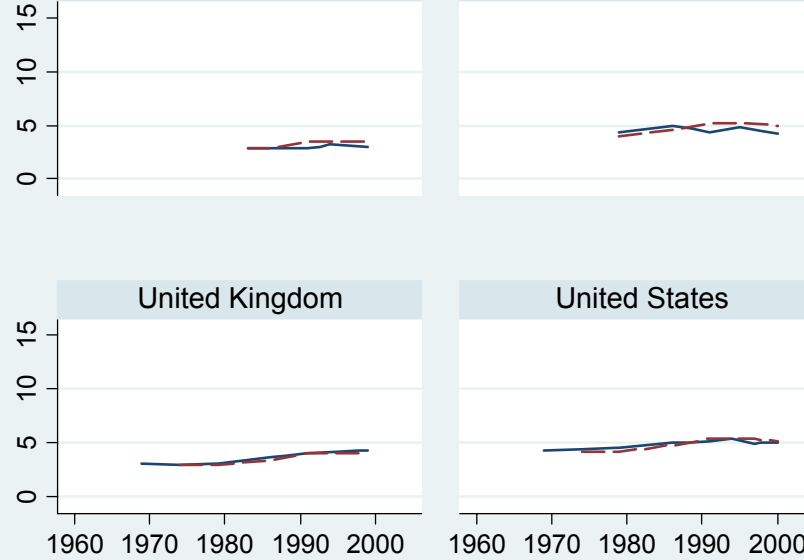

United States

19601970198019902000

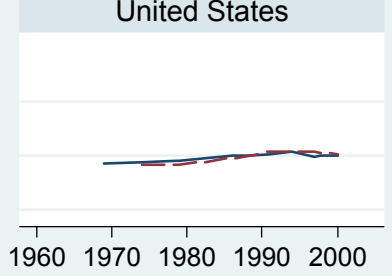

Denmark

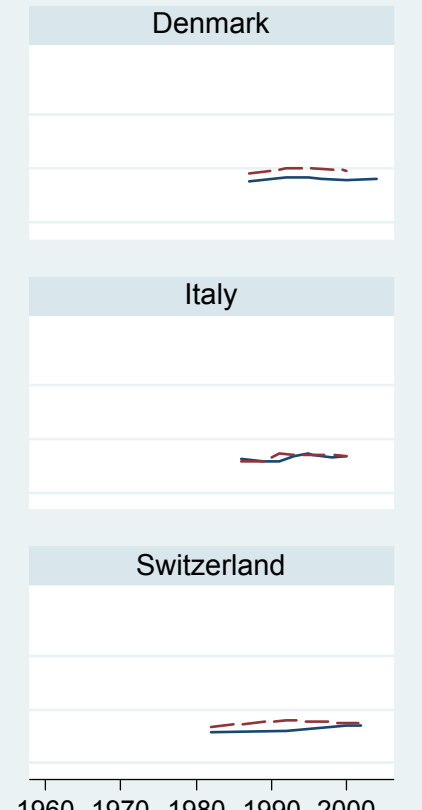

$\begin{array}{llll}1960 & 1970 & 1980 & 1990 \quad 2000\end{array}$

year

actual

predicted 


\section{Aggregate unemployment rate - actual and model prediction}

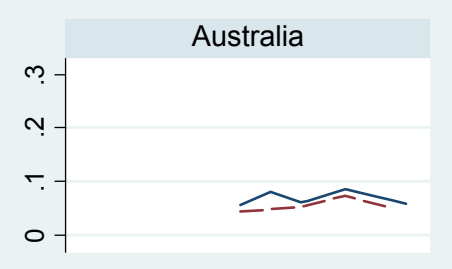

Austria

Belgium

Canada

Denmark

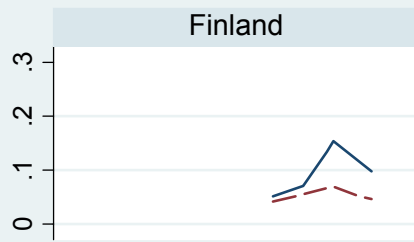

France
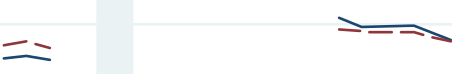

Germany

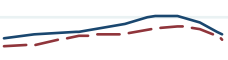

Ireland
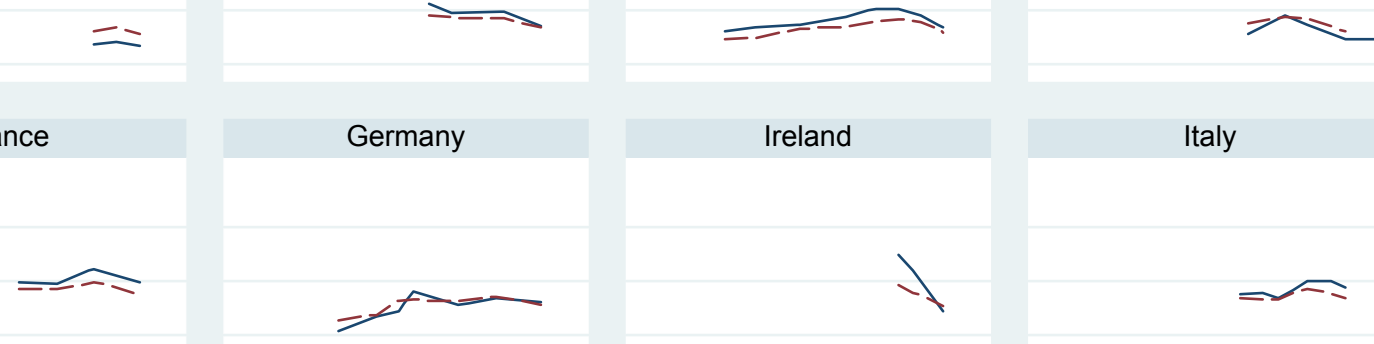

Norway

Spain
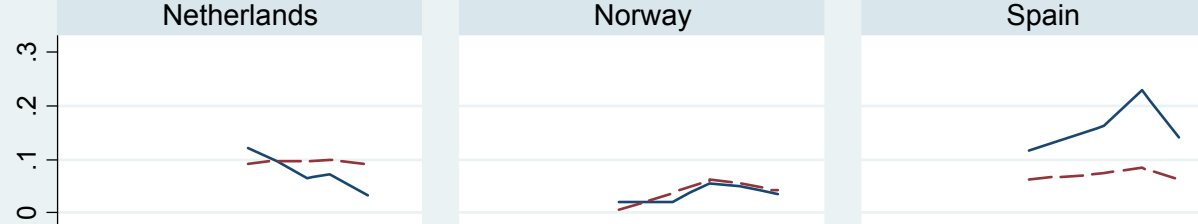

19601970198019902000
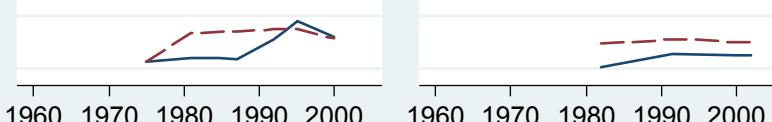

United States
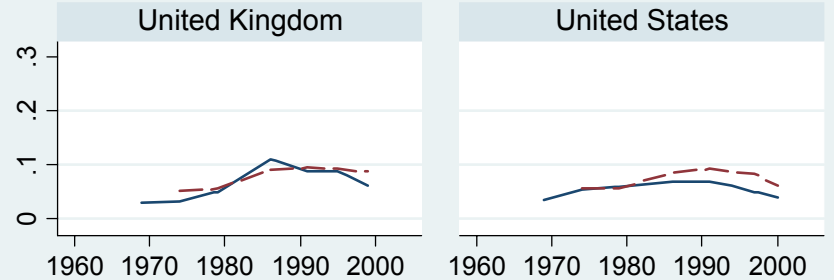

year

actual

\section{predicted}

